\title{
Bienes y servicios ecosistémicos en la planificación y gestión de áreas urbanas consolidadas
}

Ecosystem Goods and Services in Planning and Management of Consolidated Urban Areas

Bens e serviços ecossistêmicos em áreas consolidadas e gestão urbana

\author{
Rafael Francesconi Latorre ${ }^{*}$ \\ Ivonne Martínez Clavijo ** \\ Pilar Díaz Forero ${ }^{* * *}$ \\ Colaborador: Álvaro Tenjo Cruz
}

Recibido: 6 de noviembre de 2013

Aprobado: 27 de enero de 2014

Doi: dx.doi.org/10.12804/territ30.2014.09

Para citar este artículo:

Francesconi, R., Martínez, I. y Díaz, P. (2014). Bienes y servicios ecosistémicos en la planificación y gestión de áreas urbanas consolidadas. Territorios, 30, 191-218. doi: dx.doi.org/10.12804/territ30.2014.09

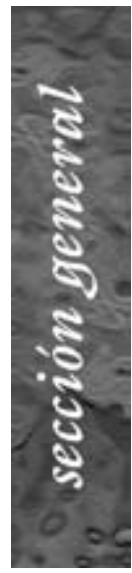

* Arquitecto de la Universidad de los Andes, Colombia, Magister en Filosofía de la Pontificia Universidad Javeriana, Colombia, candidato a Doctor en Arte y Arquitectura de la Universidad Nacional de Colombia, Sede Bogotá. Docente investigador del Programa de Arquitectura de la Universidad Piloto de Colombia en las lineas Paisaje, lugary territorio y Proyecto: Teoría, métodos y prácticas. Correo electrónico: rafael-francesconi@unipiloto.edu.co

** Arquitecta de la Universidad Piloto de Colombia, Magister en Diseño Urbano de Pratt Institute (Nueva York). Candidata a Magisteren Gestión Urbana Universidad Piloto de Colombia. Docente investigadora del Programa de Arquitectura en la Universidad Pi- $\Rightarrow$ 
Palabras clave

Ecología del paisaje, ordenamiento urbano, cobertura del suelo, tratamientos urbanisticos, consolidación urbanistica.

Keywords

Landscape ecology, urban planning, land cover, urban treatments, urban consolidation.

Palavras-chave

Ecologia da paisagem, ordenamento urbano,

cobertura do solo, tratamentos urbanisticos, consolidação urbanistica.

territarias 30

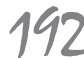

\section{RESUMEN}

En el contexto de una planificación que declara privilegiar los elementos de la estructura ecológica, pero que podría comprometer la provisión de suelos para soportar coberturas que ofrezcan bienes y servicios ecosistémicos, se presenta un aporte a la discusión sobre cómo lograr un balance entre densificación y provisión de estos bienes y servicios, mediante la reconstrucción de la transformación de la cobertura de un segmento de la cuenca del río Fucha en Bogotá en un lapso de 77 años y la verificación de las relaciones de dicha transformación con los instrumentos de planificación y gestión. Los resultados obtenidos sugieren una regulación reactiva, con limitaciones para conducir la ocupación del territorio, de la que se puede esperar una acentuación de la aridez. Estos resultados sustentan las conclusiones sobre la necesidad de replantear la regulación sobre áreas consolidadas e introducir instrumentos de gestión de la cobertura.

\section{ABSTRACT}

In a context of urban planning in which the priority of the elements of the ecological structure has been declared, but the supply of soils to support a coverage that provide ecosystem goods and services could be insufficient, it is presented a contribution to the discussion of how to achieve a balance between densification and provision of these goods and services, through reconstruction of the coverage transformation of a segment of the Fucha river basin in Bogotá in a span of 77 years and the characterization of the relations of such transformation with city planning and management instruments. The results suggest urban a paradoxical post factum urban planning, with constraints to drive the territory occupation, from which aridity intensification can be expected. These results support the conclusions on the need to rethink the regulation on consolidated urban areas and introduce coverage management instruments.

\section{RESUMO}

No contexto de uma planificação que declara privilegiar os elementos da estrutura ecológica, mas que poderia comprometer a provisão de solos para suportar coberturas que ofereçam bens e serviços ecossistêmicos, apresenta-se um aporte à discussão sobre como conseguir um balanço entre densificação e provisão destes bens e serviços, mediante a reconstrução da transformação da cobertura de um segmento da bacia do rio Fucha em Bogotá em um lapso de 77 anos e a verificação das relações de dita transformação com os instrumentos de planificação e gestão. Os resultados obtidos sugerem uma regulação reativa, com limitações para conduzir a ocupação do território, da que se pode esperar uma acentuação da aridez. Estes resultados sustentam as conclusões sobre a necessidade de reformular a regulação sobre áreas consolidadas e introduzir instrumentos de gestão da cobertura. 


\section{Introducción}

Este artículo trata sobre la relación entre la provisión de suelo para soportar coberturas que ofrecen bienes y servicios ecosistémicos y los instrumentos de planificación y gestión urbana. Su referente empírico se encuentra en el estudio de los efectos de la urbanización en la transformación de la cobertura del suelo, en un segmento de la cuenca del río Fucha (Bogotá, Colombia). Por sus características, el segmento de cuenca escogido permite aportar a la discusión sobre el balance entre densificación y provisión de bienes y servicios ecosistémicos. Este segmento ilustra un problema de incongruencia en la gestión de los elementos de la estructura ecológica principal (en adelante EEP), que se manifiesta en el contraste entre: 1) la prioridad asignada a dicha estructura, en la norma que regula el ordenamiento territorial de la ciudad en la que se ubica (artículo 16, D. 190, 2004), ${ }^{1}$ con 2) la progresiva disminución de suelo para soportar coberturas que ofrecen bienes y servicios ecosistémicos, que conduce a una creciente aridez ${ }^{2}$ de las áreas urbanas, sujetas al reemplazo de la edificaciones existentes, de acuerdo con el tratamiento urbanístico denominado 'consolidación'. De acuerdo con la caracterización de la relación entre los efectos de la urbanización en la transformación de la cobertura del suelo y los instrumentos de planificación y gestión, el contraste mencionado indicaría deficiencias en la concepción y aplicación de los instrumentos de planificación, de los de gestión, o bien, de la relación entre los dos.
La importancia de establecer si existe incongruencia entre la prioridad asignada a la EEP en la planeación física y la progresiva disminución de suelo para soportar coberturas que ofrecen bienes y servicios ecosistémicos, en las áreas urbanas sujetas al mencionado tratamiento de 'consolidación', radica en que la primera podría ocultar una paradójica pérdida de bienes y servicios ecosistémicos, ofrecidos por los elementos de la estructura ecológica principal (contrapuesta a la prioridad atribuida a esta), con efectos irreversibles en la fragmentación de los ecosistemas presentes en la ciudad y sus alrededores. Esta aparente incongruencia entre la prioridad asignada por la planificación a la EEP y la progresiva disminución de suelo para soportar coberturas que ofrecen bienes y servicios ecosistémicos, en las áreas urbanas sujetas al tratamiento de consolidación (con el consecuente incremento de la aridez de estas), lleva a la consideración de la relación entre los instrumentos de planificación, al parecer, centrados en la edificabilidad y el aprovechamiento, y los de gestión, en apariencia, incapaces de lograr una cobertura del suelo apta para ofrecer bienes y servicios ecosistémicos. Si se acepta que es acertado asignar prioridad a la EEP, se seguirá que los instrumentos de planificación de menor jerarquía se deben subordinar a la prioridad a la que se ha hecho referencia o, al menos, evitar efectos contrarios, lo que plantea una pregunta sobre si los instrumentos de planificación de menor jerarquía, como las unidades de planificación zonal (UPZ), deben contribuir a instrumentalizar esta prioridad reconoci- loto de Colombia en la línea Paisaje, lugar y territorio. Correo electrónico: ivonnemartinez@unipiloto.edu.co

*** Arquitecta de la Universidad Piloto de Colombia, Especialista en Gestión Ambiental Urbana Universidad Piloto de Colombia. Docente investigadora de la Universidad Piloto de Colombia en la línea Paisaje, lugar y territorio. Correo electrónico: pdforero@ yaboo.com

1 "Principios básicos (de la estrategia de ordenamiento para Bogotá Distrito Capital). El Territorio del Distrito Capital se ordena en el largo plazo según una estrategia que se implementará bajo tres principios básicos: el primero, la protección y tutela del ambiente y los recursosnaturalesy su valoración como sustrato básico del ordenamiento territorial." Alcaldía Mayor de Bogotá (2004). Este Decreto fue reemplazado por el Decreto 364 de 2013 de la Alcaldia Mayor de Bogotá, sin embargo la investigación recogida en este artículo se realizó con anterioridad a la expedición de este último.

2 Para efectos de la investigación el concepto de aridez se fundamenta en la relación entre la cantidad de zonas blandasyzonas duras con que cuentan las áreas urbanas para la oferta de $\Rightarrow$

tersitarios 30

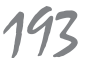


bienes y servicios ecosistémicos; entre más baja la provisión de zonas blandas es mayor la aridez.

${ }^{3}$ Los tratamientos urbanisticos son instrumentos normativos contemplados en el Plan de Ordenamiento Territorial, POT, (2000) concebidos para orientar las intervenciones en el territorio de acuerdo a las caracteristicas que lo particularizan. "El tratamiento de consolidación regula la transformación de las estructuras urbanas de la ciudad desarrollada, garantizando coherencia entre la intensidad de uso del suelo y el sistema de espacio público existente o planeado". Alcaldia Mayor de Bogotá (2000).

\section{territarias 30} 194 da a la EPP, en la ordenación del territorio, y si es necesaria la introducción de instrumentos para la gestión de coberturas que ofrezcan bienes y servicios ecosistémicos.

Con respecto a la incongruencia mencionada, el presente artículo busca presentar evidencia empírica que contribuya al esclarecimiento de la incidencia de los instrumentos de planificación, que asignan la edificabilidad y el aprovechamiento de las áreas urbanas, en la disminución de la provisión de suelo para soportar coberturas que ofrezcan bienes y servicios ecosistémicos y la creciente aridez de estas áreas, como también explorar el potencial de los instrumentos de planificación y de gestión, para facilitar su contribución a la provisión de estos bienes y servicios.

Con este propósito, a partir del reconocimiento de la situación actual del área de estudio en la que se adelanta la investigación "Compacidad urbana y restauración ecológica: Zona de transición entre la cuenca alta y media del río Fucha (Bogotá, Colombia)", de la cual forma parte el presente trabajo, se reconstruyó la transformación de la cobertura del área de estudio, como medio para constatar, de manera empírica e independiente de la regulación, un proceso de acentuación de la aridez, mediante el seguimiento en el tiempo de las áreas con cobertura arbórea y las correspondientes al corredor ripario, de la misma manera que la proporción entre suelos blandos y duros, dentro de las áreas urbanizadas. También, se estableció unidades de paisaje, para hacer operativa la verificación de las relaciones entre instrumentos de planificación y la transformación de la cobertura del suelo (es decir, entre otras cosas, para establecer si su grado de aridez actual estaba previsto en la regulación con la que se autorizó la urbanización y edificación de cada una de estas, o si puede ser asociado a la inobservancia de dichas regulaciones o a la expedición de normas posteriores, con lo que se corrobora o se desmiente la existencia de una correlación entre decisiones de planificación y el proceso de acentuación de dicha aridez). Así mismo, se reconstruyó la edificabilidad asignada en diversos momentos de planificación y se estudió su asociación con las transformaciones de las unidades de paisaje.

Desde el punto de vista metodológico, se acudió a técnicas de interpretación de imágenes suministradas por sensores remotos, para la reconstrucción de la transformación de la cobertura del suelo. La técnica aplicada para la identificación de unidades de paisaje fue el registro cartográfico de la observación directa y la interpretación de imágenes de sensores remotos. Por su parte, para reconstruir la historia de las edificabilidades asignadas se realizó investigación de archivo.

\section{Antecedentes}

\section{Del concepto de restauración ecológica al de bienes y servicios ecosistémicos de nuevos ecosistemas dentro de áreas urbanas}

En el marco del proyecto de investigación del que hace parte el presente trabajo, se ha identificado dos objetivos de la plani- 
ficación y la gestión, cuya articulación se considera deseable: compacidad urbana y restauración ecológica. En la aplicación del concepto de restauración ecológica al contexto de un territorio urbanizado, se dificulta la identificación de un estado anterior al disturbio, constituido por la urbanización misma, al que sea viable retornar, por lo que, junto con otras consideraciones, se plantea que en estos casos se proponga la creación de nuevos sistemas ecológicos, que provean bienes y servicios ecosistémicos (Díaz, 2013). La creación de estos nuevos sistemas ecológicos requiere de suelo, para el cual estos sistemas vendrían a ser su cobertura. Por otra parte, los efectos de la impermeabilización (Estrada, 2013) en el caudal, la velocidad y la calidad del agua, son susceptibles de ser interpretados como condiciones, hasta cierto punto administrables, para la creación de los nuevos ecosistemas a los que se ha hecho referencia.

\section{Del concepto de ciudad compacta al de compacidad urbana}

Desde la década de los noventa, algunos autores reconocen la existencia de una relación entre ciudad compacta y sostenibilidad. Tal es el caso del capítulo titulado "Ciudades sostenibles" del libro Ciudades para un pequeño planeta (2008 [1997]) de Richard Rogers y Philip Gumuchdjian. El concepto de ciudad compacta, al que se refieren estos autores, es ejemplificado por un proyecto para el distrito de Lu Zia Sui en Shanghái, desarrollado por la firma de servicios profesionales de diseño arquitectónico de uno de los autores. Por su parte, Salvador Rueda, en diversos trabajos, hace corresponder el concepto de ciudad compacta con un tipo histórico específico, "la ciudad compacta mediterránea" (Rueda, Cáceres, Cuchí, y Brau, 2012; Rueda, 1997). En otros contextos se discute conceptos afines como el de alta densidad (Cheng, 2010). ${ }^{4}$ En este trabajo, la compacidad se entiende no tanto como un modelo de ciudad sino como una variable de las áreas urbanas, susceptible de ser planificada y gestionada, que se puede establecer para diversas escalas, de manera afín a planteamientos de otros que le preceden (Jenks, 2000).

\section{Del estudio de coberturas a la gestión}

La discusión sobre los efectos que la densidad produce en la transformación de las zonas blandas ${ }^{5}$ en áreas urbanas consolidadas, se centra en dos aspectos en el presente artículo, la provisión de suelo urbano capaz de soportar coberturas que ofrezcan bienes y servicios ecosistémicos y la gestión de la cobertura. Estudios internacionales y locales realizados sobre coberturas, analizan el potencial de las zonas blandas en áreas urbanas para la conservación de la biodiversidad (Díaz y Armesto, 2003; Smith et al, 2005; González y Gómez, 2008; Meza, 2009; Reyes y Meza, 2011; Molina y Vargas, 2012; Osorio-Olarte, 2012), en estos estudios se demuestra la importancia de la vegetación en la provisión directa o indirecta de varios de los servicios ecosistémicos importantes para el bienestar humano en áreas urbanas, como la regulación de la
4 "Attitudes towards highdensity development are diverse. Some people acknowledge the merits of high density and advocate urban compaction, whereas others criticize the drawbacks and argue strongly against it" (Cheng, 2010, p. 14). "High building density [...] helps to reduce the pressure to develop open spaces and releases more land for communal facilities and services to improve the quality of urban living. However, some people argue that the opposite is also true. In order to achive high building density, massive high rise buildings are inevitable, and these massive structures, crammed into small sites, can conversely result in very little open space and a congested cityscape. This may happen when highdensity development is carried out without planning. Therefore, in order to avoid the negative impacts of highdensity, thorough planning and appropriate density control are essential". (Cheng, 2010, pp. 14-15) "High building density can belp to protect the countryside and agricultural land from urbanization. [...] On the other hand, high building density, which is usually in the form of high rise clusters [...] may reduce space for trees and shrubs that purify the air and cool inner urban areas. The high $\Rightarrow$

tersitarios 30

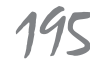


proportion of built-up mass and the loss of greenery are causes of the urban heat island effect". (Cheng, 2010, p. 15).

${ }_{5}$ Para efectos de la investigación en curso, se entiende por zonas blandas aquellas áreas urbanas con cobertura vegetal (parques, antejardines, zonas verdes, etc.) con capacidad para proveer bienes o servicios ecosistémicos y las zonas duras, aquellas áreas construidas y cuentan con cobertura vegetal (andenes, terrazas, patios construidos, balcones, decks, etc.).

6 "Lotes sin urbanizar existentes en la malla urbana; manzanas construidas parcialmente o de baja densidad; espacios verdes de carácter privado como clubes recreativos; espacios verdes de las fábricas tradicionales de las ciudades; y lotes de instituciones públicas nacionalesy departamentales, además de los de propiedad municipal" (Vélez, 2007, p. 25).

7 "Los patrones de urbanización compactos normalmente se asocian con impactos menores sobre el entorno natural, pero las complejas interacciones entre los patrones de construcción y paisajes naturales en proceso de urbanización no se conocen bien. A pesar del

tersitarios 30 196 temperatura, la reducción de la polución y de los efectos de las islas de calor, la captura y el almacenamiento de dióxido de carbono, la infiltración de aguas lluvias, la regulación de caudales, la purificación de aguas superficiales y la polinización (Reyes 2012; Molina y Vargas, 2012).

El inventario de zonas blandas estudiado contempla la contribución de áreas verdes catalogadas como vacíos ${ }^{6}$ o residuos urbanos y públicas normalmente categorizadas por la "funcionalidad urbanística en relación con el uso social" (Vélez, 2007,p. 26) como los parques urbanos, incluyendo las zonas verdes del sistema vial (separadores y andenes), sin consideraciones bióticas para su planificación. En otros estudios se ha ampliado el análisis a la contribución de las áreas privadas, específicamente de jardines domésticos y patios (Smith, , Gaston, Warren y Thompson, 2005; González -García y Gómez, 2008; Meza, 2009; Reyes y Meza, 2011) considerados recursos que requieren mayor estudio para establecer su aporte real en planes y estrategias para el mejoramiento de la calidad ambiental de la ciudad (Meza, 2009).

Si bien algunos de estos estudios se refieren a la diversidad de la vegetación y la avifauna, en común concluyen la importancia de incluir la biodiversidad en la planificación y gestión de la ciudad, aspecto abordado desde el estudio no solo ecológico y ambiental de las coberturas, sino desde el social y económico (Vélez, 2007; Molina y Vargas, 2012), y de los patrones urbanos (Alberti, 2007); la interacción del ser humano con los procesos bióticos que se dan en las coberturas, conforma patrones que Alberti (2007) en su investigación llama “firmas ecológicas" (ecologycal signatures), la investigadora sostiene que el reto de la planificación urbana es comprender a profundidad el desarrollo y el efecto de estas relaciones en la dinámica de los ecosistemas. ${ }^{7}$

La asociación de los aspectos sociales y económicos se orienta a los beneficios que las zonas blandas ofrecen en búsqueda de una mayor funcionalidad desde el punto de vista ecológico, con estrategias como la reducción de la fragmentación, el aislamiento de los espacios verdes y la búsqueda de conectividad estructural y funcional con la estructura ecológica hasta llegar a las áreas rurales, esto a partir de la provisión de suelo para espacio público (Vélez, 2007). En este marco y parafraseando Molina y Vargas (2012), los beneficios económicos no son tan evidentes por ser indirectos, ${ }^{8} \mathrm{el}$ tema se concentra en una administración inteligente y pertinente del recurso vegetal para lograr mayores beneficios individuales y en conjunto. Vélez (2007) sostiene, desde un punto vista social y ecológico, que la gestión de las coberturas implica la articulación de políticas y planes del espacio público, aunque reconoce la necesidad de asociar los espacios privados; su estudio aporta la creación de instrumentos como "fondos de pago de cesiones obligatorias urbanísticas destinados a la generación o retención de espacios verdes determinados, $[\ldots]$ e incluso como se plantea en la literatura internacional (Kendle y Forbes [1997] en Vélez, 2007), el establecimiento de contratos de arrendamiento de lotes 
naturalizados o de espacios verdes privados, de interés ecológico, a fin de conservarlos o extender en el tiempo su permanencia como suelo verde 'informal', previendo su futura formalización como áreas públicas" (Vélez, 2007, p. 25).

De la revisión de experiencias mencionadas en los estudios relacionados desde 2003 , el presente trabajo parte de la necesidad de profundizar en variables de compacidad con relación a variables ecológicas antes de plantear criterios de gestión, se enfoca en entender la articulación de instrumentos de planificación con el manejo de coberturas, para este caso, dirigida a la provisión de suelo en áreas urbanas consolidadas. El punto de partida común con las investigaciones y estudios que anteceden es el valor ecológico que las zonas blandas ofrecen por la provisión de bienes y servicios ecosistémicos.

\section{Área de estudio}

$\mathrm{El}$ área de estudio constituye un segmento de la zona de transición entre la cuenca alta y media del río Fucha en la ciudad de Bogotá D. C., entre las coordenadas $4^{\circ} 34^{\prime} 19^{\prime}$ ' norte, $74^{\circ} 4^{\prime} 47^{\prime \prime}$ ' oeste y $4^{\circ} 35^{\prime} 39^{\prime \prime}$ norte, $74^{\circ} 06^{\prime} 10.82^{\prime \prime}$ oeste, a una altura entre los $2.646 \mathrm{msnm}$ y $2.567 \mathrm{msnm}$ (Barreto y Montejo, 2013). El segmento, territorio de las localidades de San Cristóbal y Antonio Nariño que en total abarca una superficie de 561,38 hectáreas, limita al norte con la avenida La Hortúa, al este con la carrera 8A este, al sur con la avenida Primero de Mayo y al oeste con la carrera 27. Esta su- perficie se encuentra localizada en una planicie lacustre de suelos sedimentados en la cual el río cuenta con un tramo rectificado y recubierto en concreto entre las carreras 6 y 27 , y uno no canalizado de la carrera 6 al oriente (Estrada, 2013); esta configuración permitió observar la influencia de estas condiciones sobre la biodiversidad (Barreto y Montejo, 2013) y el efecto de la canalización sobre los meandros y las condiciones naturales del río (Estrada, 2013). El área se caracteriza por ser urbanísticamente consolidada, alberga cerca de 155000 habitantes distribuidos en estratos 2 y $3,{ }^{9}$ y con usos del suelo fundamentalmente residencial, comercial, dotacional e industrial.

\section{Contexto de planificación}

La transformación del tejido urbano del área de estudio se puede entender como un registro de los esfuerzos del gobierno local por conducir la ocupación urbana del territorio. Para la década de los treinta, la ciudad presentaba un crecimiento fraccionado con desarrollo de barrios aislados del centro de la ciudad, problemas abordados por Karl Brunner, en cabeza del Departamento de Urbanismo, ${ }^{10}$ con "ensanches fragmentarios" (Saldarriaga, 2006, p. 96) hacia las cuatro direcciones de la ciudad, incluyendo el barrio Ciudad Jardín hacia el sur, ensanches propuestos en función del espacio público, conservación de importantes zonas blandas y áreas específicas para equipamientos. Desde 1931 ya se reconocía la inclusión de mecanismos de planeación y gestión por lo que Lemus (2006) reconoce gran debate sobre el impacto ecológico de formas urbanas alternativas, las relaciones propuestas entre los patrones urbanos y las funciones de los ecosistemas son sólo bipótesis todavia” (Alberti, 2007, p. 56).

8 “(...) reducción de los consumos de energía eléctrica para calefacción o aire acondicionado, la reducción del indice de consultas médicas por afecciones respiratorias, la disminución de los daños causados por inundaciones, la mengua de daños a construcciones por deslaves y derrumbes, la recuperacióny/o rehabilitación de áreas erosionas, entre otros" (Molina y Vargas, 2012, p. 57).

9 "La estratificación socioeconómica es el mecanismo que permite clasificar la población en distintos estratos o grupos de personas que tienen caracteristicas sociales y económicas similares, a través del examen de las características físicas de sus viviendas, el entorno inmediato y el contexto urbanistico o rural de las mismas" (Departamento Nacional de Estadistica, $D A N E)$. La estratificación se emplea para el cobro de los servicios públicos domiciliarios con tarifas diferenciales $y$ asignación de subsidios.

${ }^{10}$ El Departamento de Urbanismo de Bogotá fue $\Rightarrow$

tersitarios 30

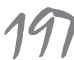


creado en 1928 como dependencia de la Secretaría de Obras Públicas Municipales, su función consistía en elaborar el plan regulador de la ciudad y expedir el código de urbanismo que lo reglamentara (Saldarriaga, 2006).

${ }^{11}$ Plan de Fomento de Bogotá y construcción de un nuevo acueducto, Acuerdo 59 de 1931 (Lemus, 2006).

12 La carta de urbanismo conocida como la Carta de Atenas publicada por Le Corbusier (1942), consigna los principios urbanisticos de la ciudad funcional, propuesta del movimiento moderno en oposición a la ciudad tradicional. En ella se propone la segregación de las funciones urbanas habitar, trabajar, recrear y circular y la racionalización del uso del suelo de acuerdo a lasactividadespor medio de la zonificación, entre otros principios.

${ }^{13}$ El indice de ocupación se refiere al área del predio susceptible de ser edificada respecto al área total.

${ }^{14}$ El indice de construcción se refiere al número máximo de metros de construcción que se puede hacer en un predio con relación al área total.

${ }^{15}$ La obligación de adopción de un plan regulador por parte de la ciudad se esta-

territarias 30 198 como el propósito de "coordinación de las distintas dependencias municipales en un proyecto que incorpora la estructura física con la organización administrativa y fiscal de la ciudad" 11 (p. 63). En esta década, la reglamentación de las urbanizaciones se da con la expedición del Acuerdo 48 de 1934, las licencias urbanísticas con el Acuerdo 20 de 1940, y los acuerdos 15 y 22 de 1940 fijaron el perímetro urbano y la zonificación de la ciudad en cuatro áreas.

En los años siguientes, ocurre lo que Montenegro (2009) describe como un "tránsito urbanístico" de ensanche a la de ciudad funcional, ${ }^{12}$ así con el Acuerdo 21 de 1944, reglamentario del Plan Soto Báteman, aumenta a siete los tipos de zona de la ciudad por usos, propone la ampliación vial y un nuevo sistema de valorización; en él se normatiza por primera vez temas como demarcación, parcela, ancho de vía, índice de ocupación (IO), ${ }^{13}$ índice de construcción (IC),${ }^{14}$ alturas, aislamientos, antejardines, tamaño de patios y baños, hoy considerados herramientas para la urbanización y construcción de la ciudad. En el novedoso marco de previsión del ordenamiento físico y de expansión de la ciudad, el Decreto 185 de 1951 oficializa el Plan Piloto de Bogotá elaborado por Le Corbusier como base para la formulación del Plan Regulador, ${ }^{15}$ instrumento de planificación de "intervención preventiva en la edificación y uso del suelo por parte de la administración distrital y construir un régimen de infracciones y sanciones urbanísticas" (Lemus, 2009, p. 75 ). Con el Plan Regulador se adoptó el nuevo perímetro urbano, zonificación y sistema vial propuesto en el Plan Piloto, que para el momento ya incluía el área de estudio; por primera vez, se plantean multifamiliares en amplias zonas verdes.

Desde finales de la década de los cincuenta se experimenta un cambio en el modelo hacia la previsión del sistema de planificación y la ciudad, y la práctica de los sistemas urbanos, concluyendo en la aplicación de principios como densidad y redistribución de actividades (Lemus, 2009). El crecimiento descontrolado que experimenta la ciudad se trata de regular con el reparto de la tierra según los usos del suelo, el área y los frentes mínimos de los lotes, así como las cesiones al Distrito para áreas públicas (Acuerdo 30 de 1961). Con el Decreto 159 de 1974 se impone la planeación-acción a escala zonal sobre la tradicional planeación general lo que produjo efectos como la sustitución del barrio o urbanización por loteo individual por las agrupaciones de vivienda y conjuntos, la sustitución de la vivienda unifamiliar en lote individual por la vivienda multifamiliar en conjunto, desarrollo de los primeros procesos de densificación (predio a predio) y desarrollos de vivienda de alta densidad en la periferia del centro (Lemus, 2006), a pesar de que no contaba con los instrumentos administrativos y financieros para su desarrollo (Saldarriaga, 2006).

El cambio de paradigma de la planificación de las décadas anteriores y la introducción de un mecanismo de financiamiento habitacional basado en transformación a plazos (Sistema de Unidades de Poder Adquisitivo Constante, UPAC) revelaron 
un desfase entre la norma y la realidad de la ciudad. El Acuerdo 07 de 1979 plantea un nuevo sistema de reglamentación urbana considerado plan y norma. El Acuerdo introduce el concepto de tratamiento urbanístico como herramienta para la delimitación de las normas urbanísticas y arquitectónicas consecuente a la estructura y régimen de un área de actividad creando así, como la califica Saldarriaga (2006), una "ciudad inmobiliaria" basada en conceptos de forma y estructura. El Plan de Ordenamiento Físico (Acuerdo 06 de 1990) sustituye esos conceptos por el de niveles de zonificación para introducir jerarquía en la formulación de la normativa urbana e introduce un régimen de licencias y permisos de urbanización y construcción. Pero es la Ley 9 de 1989 la que impone una política urbana con un modelo holístico de planificación; la Ley introduce principios e instrumentos dirigidos a un reparto equitativo de las cargas de la urbanización y la construcción.

Posteriormente, con la Ley 388 de 1997 , con nuevos principios e instrumentos de planeación y gestión del territorio, se modifica y complementa la legislación existente, "fomenta la adopción de sistemas de planeación continua, basados en el recurso de instrumentos de gestión urbanística (unidades de actuación, integración inmobiliaria), de manejo del suelo (desarrollo prioritario, cesiones para el espacio público, enajenación forzosa, expropiación) y económicos (reparto de cargas y beneficios, plusvalías, fondos de compensación)" (Lemus, 2006, p. 109). En este marco, el
Decreto 619 de 2000 adopta el Plan de Ordenamiento Territorial, POT, el cual crea las unidades de planeación urbanística (UPZ), herramienta de planeación para el desarrollo de normas urbanísticas por sectores a un nivel más detallado consecuente a las dinámicas propias de la zona. El decreto 190 de 2004 recoge las modificaciones y compila las normas de los decretos distritales 619 de 2000 y 469 de 2003, que conforman el Plan de Ordenamiento Territorial de Bogotá, D. C.

\section{Metodología}

Tomando en consideración el planteamiento según el cual la compacidad se puede entender como una variable susceptible de ser planificada y gestionada para un área urbana, se ha estudiado la relación entre la provisión de suelo para soportar coberturas que ofrecen bienes y servicios ecosistémicos y los instrumentos de planificación y gestión urbana. Con respecto a las tres ventanas de tiempo estudiadas en la investigación de la que hace parte este trabajo: geológica, antrópica e histórica (Díaz, 2013), el presente artículo se concentra en la ventana histórica, en la cual se aborda el efecto que ejerce la ocupación antrópica en la transformación del territorio, como estudia Díaz (2013) de manera específica para la mencionada investigación, en el proceso de desecación del suelo. Mediante el análisis multitemporal, para la reconstrucción de la transformación de la cobertura, y el análisis de la densidad edificatoria, para la reconstrucción de la asignación de apro- blece en la Ley 88 de 1947, la cual, por primera vez, aborda el tema del desarrollo urbano. Los consultores Wiener y Sert formularon el Plan Regulador para Bogotá, oficializado con el Decreto 34 de 1952.

territarias 30 199 
${ }^{16}$ Imagen Google Earth Pro. Image 2013, Digital Globe. Fecha de imagen 3/26/2013 capturada el 17/06/2013. 4³4' 55.90" $\mathrm{N} 74^{\circ} 05^{\prime} 20.89$ ” $\mathrm{O}$ elevanción $0 \mathrm{~m}$.

${ }^{17}$ La ortorectificación elimina los efectos de la inclinación y del desplazamiento por relieve en las fotografías. "El proceso... remueve la distorsión geométrica presente en las imágenes y que está ocasionada por la orientación de la cámara o el sensor, el desplazamiento debido al velieve y los errores sistemáticos asociados con la imagen... las imágenes ortorectificadas han sido aceptadas como imágenes $i d e a l e s$ de referencia necesarias para la creación y mantenimiento de los datos vectoriales almacenados en un SIG" (Erdas, 2001, p. 2).

\section{territarias 30} 200 vechamiento y edificabilidad, se pretende mostrar cómo la aridez es producto del proceso de urbanización y las decisiones de planificación y gestión urbana.

\section{Análisis multitemporal}

Para la reconstrucción de la transformación de la cobertura del suelo se acudió a técnicas de interpretación de imágenes suministradas por sensores remotos. Esta reconstrucción corresponde a los últimos 77 años de la ventana histórica. De acuerdo con la disponibilidad de la fuente (Instituto Geográfico Agustín Codazzi, IGAC), se recopiló aerofotografías correspondientes a 12 años, entre 1936 y 2004. Para completar una serie de 13 años, incluyendo el estado de las coberturas en 2013 , se acudió a una imagen satelital. ${ }^{16}$ Con el fin de incorporar en una sola imagen diferentes tomas de sobrevuelos del área de estudio, las fotografías aéreas, adquiridas del IGAC para el proyecto de investigación, fueron sometidas a un proceso de ortorectificación ${ }^{17}$ y georeferenciación.

Esta fuente implicó dos limitaciones. Por un lado, la irregularidad de los intervalos entre los años disponibles y, por otro, la imposibilidad de una reconstrucción completa del área de estudio para cada uno de los años de la serie. En el primer caso, los intervalos oscilan entre 1 y 16 años; mientras que, en el segundo, el porcentaje de la superficie del área de estudio, cuya imagen fue posible reconstruir, varía entre el $71 \%$ y el $100 \%$ (ver tabla 1). Con respecto a esta última limitación, se decidió no considerar en el análisis la información correspondiente a los años en los que la imagen reconstruida abarcara menos de $80 \%$ del área de estudio, lo que supuso no tener en cuenta las imágenes correspondientes a dos de los años de la serie, con lo cual esta se redujo a 11, mientras que el intervalo mínimo entre años considerados pasó a 3 (ver tabla 2).

La definición del tipo de coberturas para el análisis se basó en criterios de uso y ocupación del suelo, resultando así pastizales y cultivos, cobertura arbórea, ronda natural del río, cuerpos de agua, zonas húmedas, áreas verdes, área urbanizada y área edificada. Estas coberturas se categorizaron en zonas duras y zonas blandas de acuerdo al potencial para ofrecer bienes y servicios ecosistémicos en áreas urbanas (Reyes y Figueroa 2010 2011; Molina y Vargas, 2012). La categorización de las

Tabla 1. Intervalos del análisis multitemporal

\begin{tabular}{|l|r|r|r|r|r|r|r|r|r|r|r|r|r|}
\hline \multicolumn{1}{|c|}{ Año } & 1936 & 1940 & 1949 & 1951 & 1955 & 1971 & 1976 & 1981 & 1991 & 1992 & 1994 & 2004 & 2013 \\
\hline ha & 521,63 & 561,38 & 397,48 & 458,37 & 478,88 & 561,38 & 561,38 & 513,80 & 559,55 & 417,97 & 561,38 & 545,98 & 561,38 \\
\hline$\%$ & 92,92 & 100,00 & 70,80 & 81,65 & 85,30 & 100,00 & 100,00 & 91,53 & 99,67 & 74,45 & 100,00 & 97,26 & 100,00 \\
\hline $\begin{array}{l}\text { Inter- } \\
\text { valo }\end{array}$ & & 4 & 9 & 2 & 4 & 16 & 5 & 5 & 10 & 1 & 2 & 10 & 9 \\
\hline
\end{tabular}

Fuente: Elaboración de los autores. El porcentaje expresa la extensión reconstruida por año con respecto al área total de estudio. 
Tabla 2. Intervalos finales de análisis multitemporal

\begin{tabular}{|l|c|r|r|r|r|r|r|r|r|r|r|}
\hline \multicolumn{1}{|c|}{ Año } & 1936 & 1940 & 1951 & 1955 & 1971 & 1976 & 1981 & 1991 & 1994 & \multicolumn{1}{c|}{2004} & 2013 \\
\hline ha & 521,63 & 561,38 & 458,37 & 478,88 & 561,38 & 561,38 & 513,80 & 559,55 & 561,38 & 545,98 & 561,38 \\
\hline$\%$ & 92,92 & 100,00 & 81,65 & 85,30 & 100,00 & 100,00 & 91,53 & 99,67 & 100,00 & 97,26 & 100,00 \\
\hline Intervalo & & 4 & 11 & 4 & 16 & 5 & 5 & 10 & 3 & 10 & 9 \\
\hline
\end{tabular}

Fuente: Elaboración de los autores. zonas blandas se basó en la observación agrupada de las coberturas que ofrecen bienes y servicios ecosistémicos: cultivos y pastizales, cobertura arbórea, ronda natural del río, cuerpos de agua, zonas húmedas y áreas verdes (ver figura 1); y las zonas duras aquellas con atributos de carácter urbanístico: área urbanizada y área edificada. La construcción de indicadores de aridez parte del estudio comparativo de la composición de zonas blandas con las zonas duras, específicamente respecto al área edificada.

\section{Unidades de paisaje}

Para la identificación de unidades de paisaje se realizó un registro cartográfico de la observación directa, que se corroboró con la interpretación de imágenes de sensores remotos. ${ }^{18}$ La cartografía empleada como base para el mencionado registro fue el plano digital oficial de Bogotá D. C. del IGAC en 2002.

Para la diferenciación de unidades de paisaje se tuvo en cuenta dos criterios: la
Figura 1. Análisis multitemporal, composición de zonas blandas

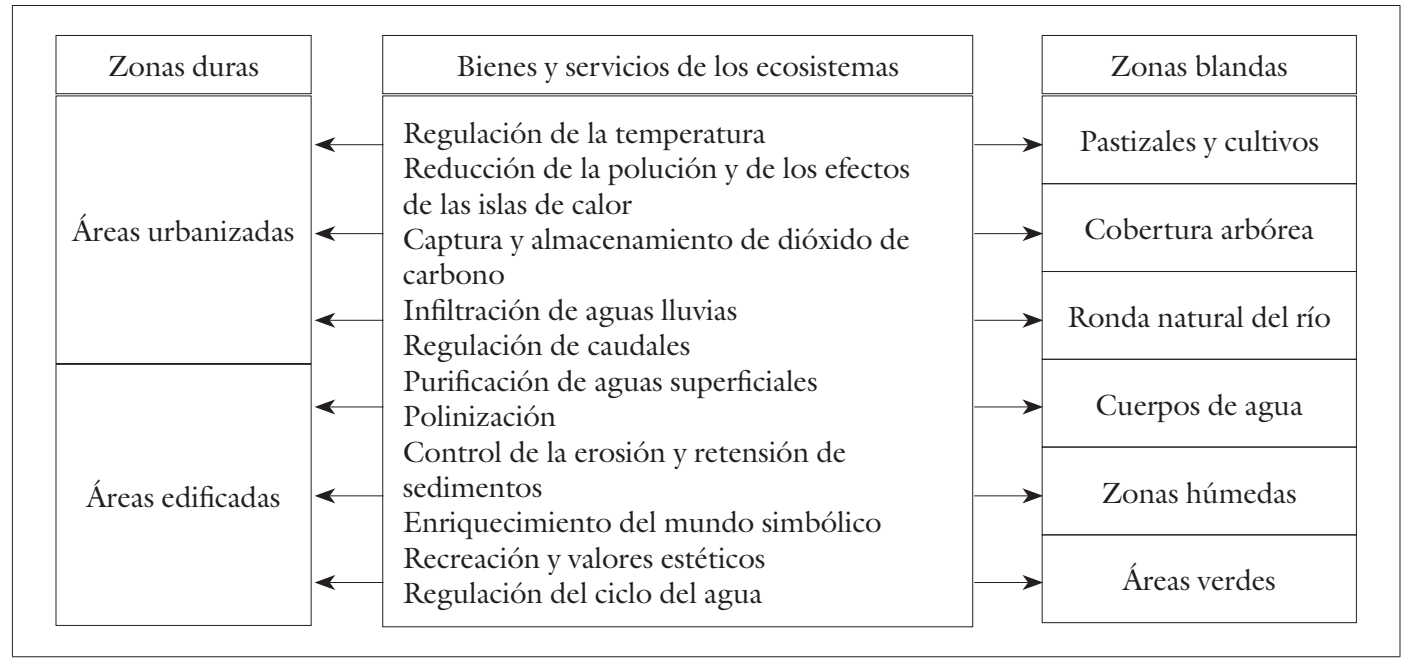

Fuente: Elaboración de los autores.
${ }^{18}$ Interpretación de imagen de satélite del año 2002 suministrada por la Secretaría Distrital de Ambiente. \\ territarias 30 201}


19 Normativa vigente $d u$ rante el desarrollo del análisis de edificabilidad de la investigación.

${ }^{20}$ Información de Unidad Administrativa Especialde Catastro Distrital.

\section{territarias 30} 202 ocupación del suelo y su uso. Por su parte, los descriptores de la ocupación del suelo se agruparon en dos categorías: áreas construidas y áreas libres. En la descripción de las áreas construidas se tuvo en cuenta, la altura (número de pisos), la ocupación y la construcción (registradas por sus respectivos índices). En cuanto a la descripción de las áreas libres, se distinguió entre aquellas que ofrecen suelos blandos, susceptibles de soportar una cobertura que ofrezca bienes y servicios ecosistémicos, de aquellas que no cuentan con este tipo de suelos. La caracterización de las áreas construidas permitió distinguir dos grupos de tipos de unidad de paisaje. Son características del primer grupo el predominio de edificaciones de tres o menos pisos, así como índices de construcción relativamente bajos e índices de ocupación relativamente altos. Por su parte, este segundo grupo se diferencia por tener índices de construcción mayores e índices de ocupación menores que los del primer grupo, así como alturas superiores a tres pisos. Estos dos grupos de tipos de edificación se cruzaron con la presencia o ausencia de suelos blandos. Con base en estas clasificaciones, se identificó nueve tipos de unidad de paisaje, relativamente homogéneas en cuanto la provisión de suelo para soportar coberturas capaces de ofrecer bienes y servicios ecosistémicos (ver tabla 3 ).

\section{Estudio de edificabilidad}

Para la determinación de la aridez, dentro del marco de la compacidad, es importan- te la medida de la densidad edificatoria, la cual se relaciona con el índice de edificabilidad (floor area ratio, FAR), entendida para efectos del presente estudio, como el área edificable de construcción neta por cada metro cuadrado de superficie neta de un predio (IGAC, 2003). Para este efecto, el análisis de edificabilidad se realizó por unidades de paisaje y comparativo entre tres momentos destacados: la aprobación inicial de urbanización, la normativa dictada en el marco del POT $(2004)^{19}$ y la situación actual de ocupación (2013). ${ }^{20}$

$$
\begin{aligned}
& \text { - Índice de } \\
& \text { edificabilidad }
\end{aligned}=\begin{gathered}
\begin{array}{c}
\text { Área máxima de } \\
\text { construcción permitida }
\end{array} \\
\frac{\text { Superficie neta del predio }}{}
\end{gathered}
$$

Las variables establecidas dentro de las normas generales de planificación, determinantes del nivel de edificabilidad y consideradas para el estudio, son los índices de construcción (plot ratio) y de ocupación (site coverage), el primero entendido como el resultado de dividir el total del área bruta de los pisos de una construcción, entre la superficie del lote (Cheng, 2010, p. 5) y el segundo, definido como el resultado de dividir la superficie correspondiente a la proyección de los pisos superiores, entre el área del lote (Cheng, 2010, p. 6). Como vía para entender el papel de la planificación se incluyó también el tamaño de los lotes y para el cálculo final de la edificabilidad la altura en pisos y el área neta en los tres momentos. Para resolver la heterogeneidad de la información en la fuente, para algunos casos se recurrió al cálculo de variables a 
Tabla 3. Tipos de ocupación del suelo por unidades de paisaje

\begin{tabular}{|c|c|c|c|c|c|}
\hline \multicolumn{5}{|c|}{ Criterios } & \multirow{5}{*}{ Tipo de unidad de paisaje } \\
\hline \multirow{4}{*}{ Áreas construidas } & \multicolumn{4}{|c|}{ Áreas libres } & \\
\hline & \multicolumn{4}{|c|}{ Zonas blandas en áreas } & \\
\hline & \multicolumn{2}{|l|}{ Privadas } & \multicolumn{2}{|c|}{ Públicas } & \\
\hline & $\begin{array}{l}\text { Patio } \\
\text { interior }\end{array}$ & Antejardín & Andén & Separador & \\
\hline \multirow{7}{*}{$\begin{array}{l}\text { Edificación } \\
\text { continua de baja } \\
\text { altura, con índices } \\
\text { de construcción } \\
\text { relativamente bajos e } \\
\text { índices de ocupación } \\
\text { relativamente altos }\end{array}$} & Sí & Sí & Sí & Sí & $\begin{array}{l}\text { Áreas con mayor provisión de zonas blandas y } \\
\text { diversidad en la cobertura (Con zonas blandas } \\
\text { tanto áreas públicas como privadas) }\end{array}$ \\
\hline & Disminución & Sí & Sí & Sí & $\begin{array}{l}\text { Áreas con antejardín, posible patio interior y } \\
\text { zona blanda sobre andén (Con disminución de } \\
\text { zonas blandas en áreas privadas, patios, pero no } \\
\text { antejardines). }\end{array}$ \\
\hline & Disminución & Disminución & Sí & Sí & $\begin{array}{l}\text { Áreas con disminución de zonas blandas. (Con } \\
\text { disminución de zonas blandas en áreas privadas, } \\
\text { tanto patios como antejardines) }\end{array}$ \\
\hline & No & Sí & No & No & $\begin{array}{l}\text { Áreas con antejardín (Con áreas blandas en } \\
\text { superficies privada, sólo en antejardines) }\end{array}$ \\
\hline & No & No & Sí & Sí & $\begin{array}{l}\text { Árida con zonas blandas sobre andén y separador } \\
\text { vial (2). Con áreas blandas sólo en superficies } \\
\text { públicas (andenes y separadores) }\end{array}$ \\
\hline & No & No & Sí & No & $\begin{array}{l}\text { Áreas áridas al interior de la manzana Con áreas } \\
\text { blandas en superficies públicas, sólo en andenes }\end{array}$ \\
\hline & No & No & No & No & $\begin{array}{l}\text { Áreas áridas (sin zonas blandas ni áreas públicas } \\
\text { ni privadas) }\end{array}$ \\
\hline \multirow{2}{*}{$\begin{array}{l}\text { Edificación en } \\
\text { altura, con índices } \\
\text { de construcción } \\
\text { relativamente altos e } \\
\text { índices de ocupación } \\
\text { relativamente bajos }\end{array}$} & \multicolumn{4}{|c|}{ Con zonas blandas } & Áreas ocupadas en altura con zonas blandas \\
\hline & \multicolumn{4}{|c|}{ Sin zonas blandas } & Áreas ocupadas en altura sin zonas blandas \\
\hline
\end{tabular}

Fuente: Elaboración de los autores.

partir de la lectura de los planos aprobados y los datos dispersos en los folios del archivo de la Secretaría Distrital de Planeación (SDP) de Bogotá D. C., con la aplicación de las fórmulas empleadas para el cálculo del aprovechamiento urbanístico (IGAC, 2003, p. 33).

- Área máxima de construcción = permitida

\section{Volumen máximo permitido \\ Altura piso tipo}


${ }^{21}$ Investigación documental en el archivo y planoteca de la Secretaría Distrital de Planeación de Bogotá (SDP).

${ }^{22}$ La explicación de las unidades de paisaje se amplia en el subtitulo "Establecimiento de las unidades de paisaje" del aparte "Resultados" del presente artículo.

\section{territarias 30} 204
- (IC) Índice de = construcción
Índice de ocupación
* altura máxima permitida en pisos

- (IO) Índice de ocupación $=$

Área proyección de pisos superiores

Superficie del predio

- Superficie bruta = Área total de planificación

- Superficie neta = Área bruta menos las áreas correspondientes a dotaciones urbanísticas públicas (vías, parques, equipamientos)

- Volumen máximo permitido Índice de ocupación

$$
\begin{array}{r}
=\quad{ }^{*} \text { superficie neta del predio } \\
\quad \text { * altura máxima permitida }
\end{array}
$$

La información del momento uno: 'aprobación inicial de urbanización', se construyó a partir de la revisión documental de los actos administrativos de aprobación del $56 \%$ de los barrios que conforman el área de estudio. ${ }^{21} \mathrm{La}$ construcción de la información de los barrios más antiguos carece de registros, lo que obligó la consulta complementaria de información secundaria como en los casos de los barrios San Javier y Restrepo; el barrio La Hortúa fue excluido del estudio por su dedicación exclusiva para equipamiento metropolitano. Para el caso de los multifamiliares se construyó la información del $43 \%$ de los conjuntos con registro por barrio con investigación documental, del $56 \%$ no se ubicó los archivos ni se encontró registros de otras fuentes. Una vez construidas las variables, se cruzó la información por barrio y conjunto con las unidades de paisaje y se ponderó la participación por unidad para el cálculo de la edificabilidad promedio.

El estudio diferenciado de barrios y conjuntos multifamiliares obedece a la construcción de las unidades de paisaje 7 (áreas ocupadas en altura con zonas blandas) y 8 (áreas ocupadas en altura sin zonas blandas). ${ }^{22}$ La investigación documental permitió la construcción de información para la unidad 7 y obligó la exclusión de la unidad 8 por falta de información.

Para el momento dos, 'normativa dictada en el marco del РОт (2004)', las fuentes de consulta fueron las UPZ número 33-Sosiego, 35-Ciudad Jardín y el proyecto de decreto para la reglamentación de la UPZ 38-Restrepo. El estudio se realizó en sectores normativos por tratamiento urbanístico cruzado con las unidades de paisaje y ponderado para el cálculo de la edificabilidad promedio.

El momento tres, 'actual (2013)', se trabajó con información de Catastro. El cálculo de edificabilidad promedio por unidad de paisaje se hizo a partir de la lectura de la información suministrada en 15 planchas digitales que cubren el $80 \%$ de la superficie de estudio a partir del loteo, perímetro de manzana, zonas verdes, área de construcciones y manzanas (mapa 1). El levantamiento de alturas se realizó con registro cartográfico de la observación directa. 


\section{Resultados}

\section{Transformación de coberturas}

La superficie del área de estudio, cubierta por edificaciones, pasó del $12 \%$, en 1936, al $84 \%$, en 2013 . Esta variación indica que el área de estudio pasó de una ocupación suburbana a una completamente urbana, durante el periodo analizado. Dado este proceso de ocupación del territorio por edificaciones, se puede esperar que la edificación se haya hecho a expensas de la cobertura correspondiente a 'pastizales y cultivos'. En efecto, esta cobertura disminuyó hasta desaparecer en el periodo comprendido entre 1936 y 1971 . Así como se podría esperar que la superficie edificada creciera

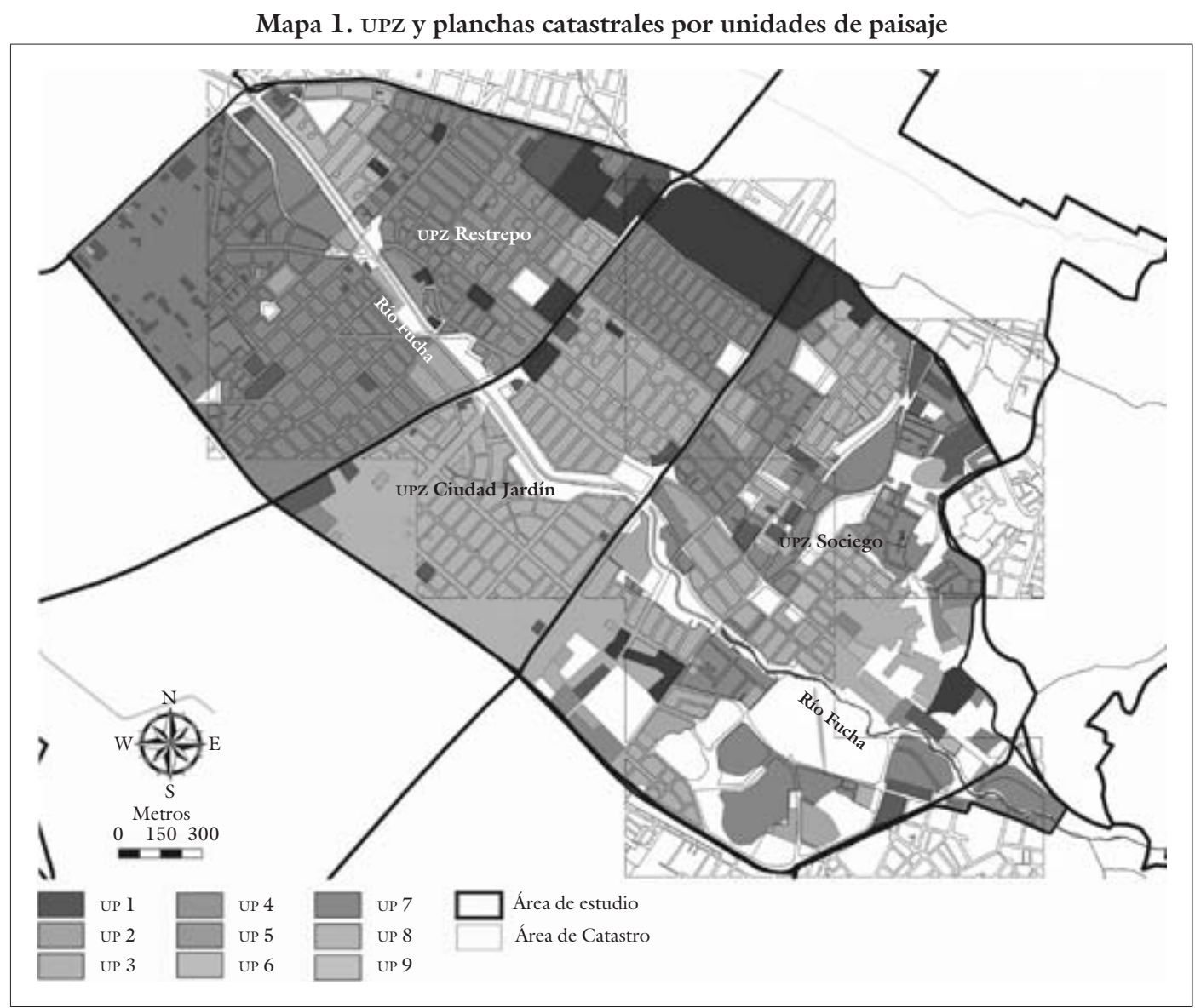

Fuente: Proyecto de investigación "Compacidad urbana y restauración ecológica: zona de transición entre la cuenca alta y media del río Fucha (Bogotá, Colombia)”. 
a expensas de la que corresponde a 'pastizales y cultivos', habría sido deseable que coberturas como la 'arbórea' y las asociadas a 'cuerpos de agua' y a la 'ronda natural del río', se hubieran mantenido. No obstante, esta expectativa se ve contrariada por una disminución acelerada de la 'cobertura arbórea', que pasó de cerca del $6 \%$ a menos del $1 \%$, entre 1936 y 1955, después de lo cual registra un proceso de recuperación que, para 2013, no alcanza la mitad del porcentaje inicial (tabla 4, mapas 2, 3 y 4 ).

En lo que respecta a la superficie cubierta por 'cuerpos de agua', se observa una disminución progresiva, durante la mayor parte del periodo observado, desde un porcentaje inicial del $1 \%$ a cerca de la mi- tad de este valor. Por su parte, la cobertura propia de la 'ronda natural del río' registra unos valores semejantes a los anotados al hacer referencia a la 'cobertura arbórea', con una reducción del porcentaje ocupado por esta, de algo más del 6\%, en 1936, a un mínimo de 0,35\%, en 1976, con una recuperación aún más leve que la de la arbórea, que alcanza el 0,61\%, en 2013. Estas cifras sugieren que la cobertura correspondiente a 'edificaciones', no solo habría consumido superficies antes ocupadas por 'cultivos y pastizales', sino que también habría afectado aquellas con mayor vocación para ofrecer bienes y servicios ecosistémicos. Habida consideración de su potencial para compensar las disminuciones indicadas en el

Tabla 4. Transformación de coberturas

territarios 30 206

\begin{tabular}{|c|c|c|c|c|c|c|c|c|c|c|c|c|c|c|c|c|}
\hline \multirow{2}{*}{ Año } & \multicolumn{2}{|c|}{$\begin{array}{c}\text { Área } \\
\text { urbanizada }\end{array}$} & \multicolumn{2}{|c|}{$\begin{array}{c}\text { Área } \\
\text { edificada }\end{array}$} & \multicolumn{2}{|c|}{$\begin{array}{l}\text { Pastizales } \\
\text { y cultivos }\end{array}$} & \multicolumn{2}{|c|}{$\begin{array}{c}\text { Cobertura } \\
\text { arbórea }\end{array}$} & \multicolumn{2}{|c|}{$\begin{array}{l}\text { Ronda natu- } \\
\text { ral del río }\end{array}$} & \multicolumn{2}{|c|}{$\begin{array}{c}\text { Cuerpos de } \\
\text { agua }\end{array}$} & \multicolumn{2}{|c|}{$\begin{array}{c}\text { Zonas } \\
\text { húmedas }\end{array}$} & \multicolumn{2}{|c|}{ Áreas verdes } \\
\hline & $b a$ & $\%$ & $b a$ & $\%$ & $b a$ & $\%$ & $b a$ & $\%$ & $b a$ & $\%$ & $b a$ & $\%$ & $b a$ & $\%$ & $b a$ & $\%$ \\
\hline 1936 & 162,57 & 31,17 & 64,47 & 12,36 & 243,99 & 46,78 & 29,37 & 5,63 & 28,49 & 5,46 & 5,42 & 1,04 & & & & \\
\hline 1940 & 199,55 & 35,55 & 88,05 & 15,68 & 237,17 & 42,25 & 16,32 & 2,91 & 17,96 & 3,20 & 5,96 & 1,06 & 0,60 & 0,11 & & \\
\hline 1951 & 113,26 & 24,71 & 97,61 & 21,29 & 222,11 & 48,46 & 10,96 & 2,39 & 23,37 & 5,10 & 4,85 & 1,06 & 1,02 & 0,22 & 1,16 & 0,25 \\
\hline 1955 & 147,18 & 30,73 & 179,49 & 37,48 & 121,28 & 25,33 & 4,55 & 0,95 & 25,29 & 5,28 & 4,14 & 0,86 & 1,13 & 0,24 & 3,35 & 0,70 \\
\hline 1971 & 121,33 & 21,61 & 391,10 & 69,67 & & & 10,13 & 1,80 & 2,14 & 0,38 & 3,32 & 0,59 & & & 40,38 & 7,19 \\
\hline 1976 & 89,23 & 15,89 & 421,16 & 75,02 & & & 8,23 & 1,47 & 1,94 & 0,35 & 3,32 & 0,59 & & & 43,67 & 7,78 \\
\hline 1981 & 45,62 & 8,88 & 426,59 & 83,03 & & & 5,63 & 1,10 & 1,93 & 0,38 & 2,85 & 0,56 & & & 36,53 & 7,11 \\
\hline 1991 & 64,05 & 11,45 & 445,24 & 79,57 & & & 12,00 & 2,15 & 3,58 & 0,64 & 3,39 & 0,61 & & & 44,86 & 8,02 \\
\hline 1994 & 47,74 & 8,50 & 504,24 & 89,82 & & & 10,82 & 1,93 & 3,40 & 0,61 & 2,76 & 0,49 & & & 46,32 & 8,25 \\
\hline 2004 & 39,40 & 7,22 & 455,69 & 83,46 & & & 14,32 & 2,62 & 3,40 & 0,62 & 2,74 & 0,50 & & & 39,66 & 7,26 \\
\hline 2013 & 39,40 & 7,02 & 471,17 & 83,93 & & & 14,32 & 2,55 & 3,40 & 0,61 & 2,74 & 0,49 & & & 39,78 & 7,09 \\
\hline
\end{tabular}

Fuente: Elaboración de los autores. 
Mapa 2. Cartografía multitemporal 1940

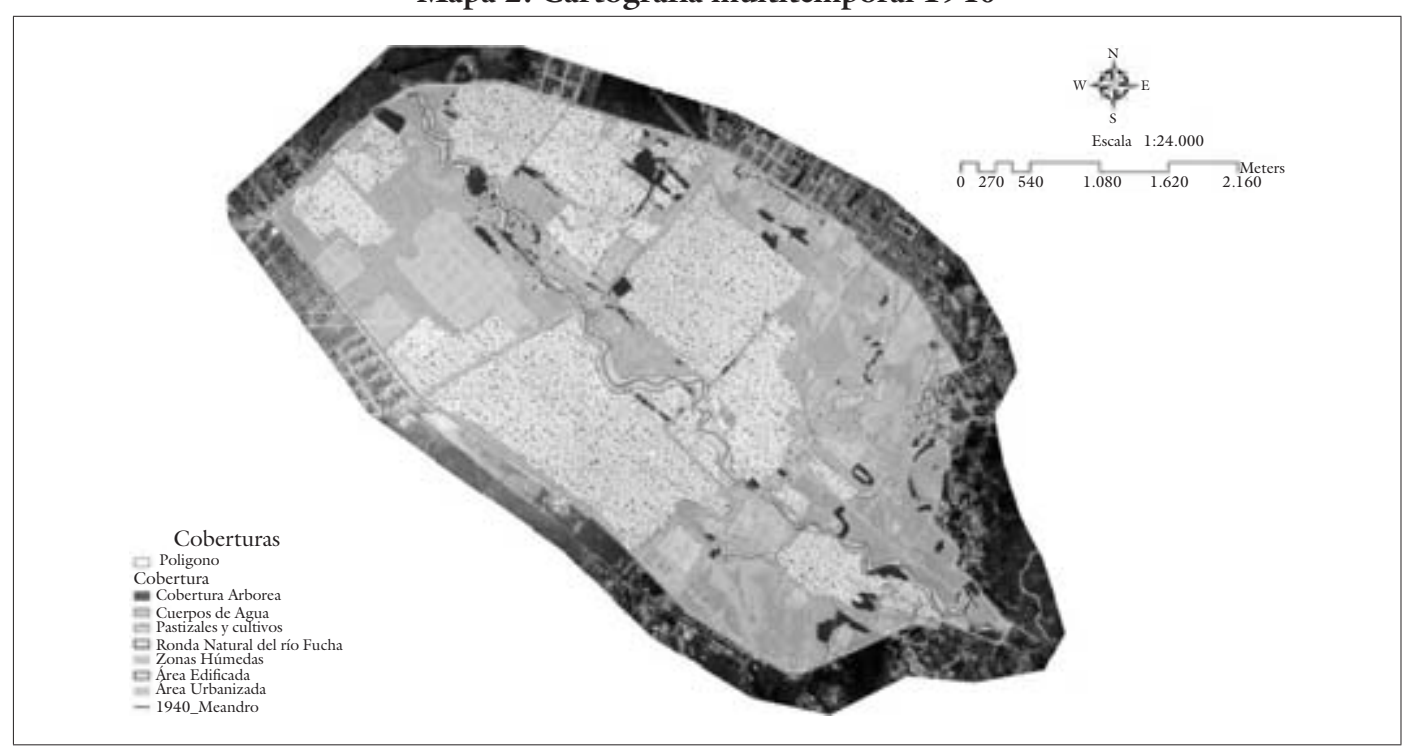

Fuente: Proyecto de investigación "Compacidad urbana y restauración ecológica: zona de transición entre la cuenca alta y media del río Fucha (Bogotá, Colombia)”.

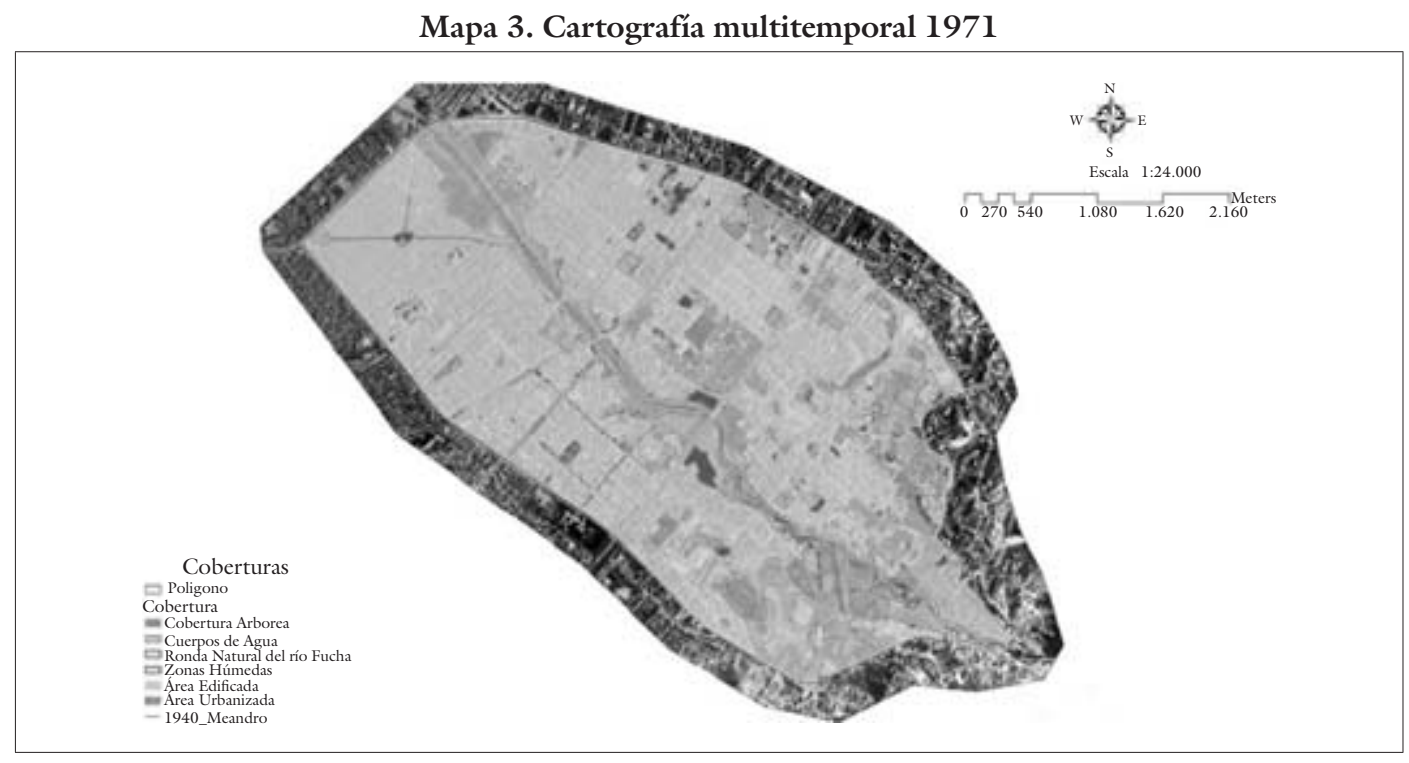

Fuente: Proyecto de investigación "Compacidad urbana y restauración ecológica: zona de transición entre la cuenca alta y media del río Fucha (Bogotá, Colombia)”. 


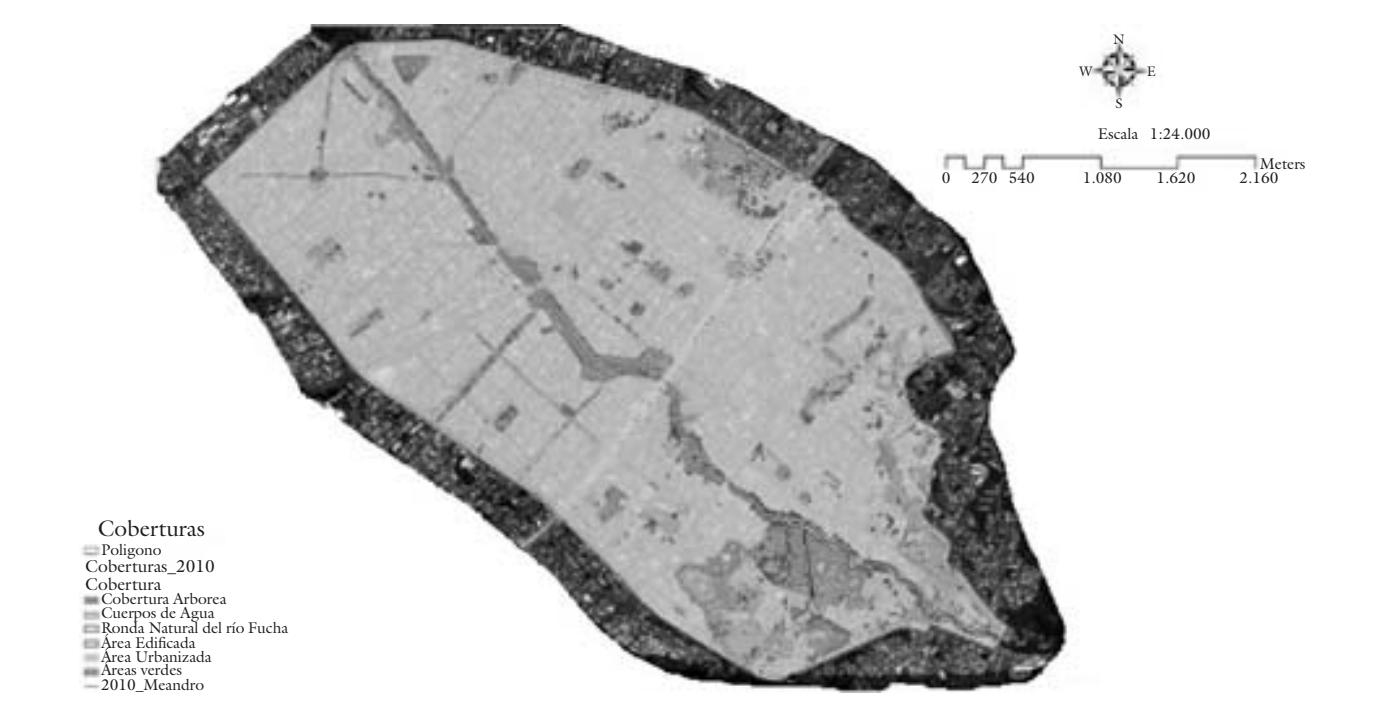

Fuente: Proyecto de investigación “Compacidad urbana y restauración ecológica: zona de transición entre la cuenca alta y media del río Fucha (Bogotá, Colombia)”.

porcentaje ocupado por las coberturas más favorables para la oferta de bienes y servicios ecosistémicos, cabe anotar la evolución del porcentaje destinado a 'áreas verdes'. Este pasa de registros iniciales bajos, de $0,25 \%$ y $0,7 \%$, en 1951 y 1955 , respectivamente, a una oscilación entre un mínimo de 7,11\% y un máximo de $8,25 \%$, durante el periodo comprendido entre 1971 y 2013, lo que sugiere un relativo éxito en la provisión de este tipo de cobertura, dentro de los procesos de planificación y gestión de las coberturas 'urbanización' y 'edificación' (figura 2). Sin embargo, cabe destacar que la correlación entre estas coberturas pasa del 0,96, en el periodo comprendido entre 1936 y 1971 , al 0,43 entre 1971 y 2013 , en un cálculo que incluye las reconstrucciones de cobertura con representatividad superior al $80 \%$ de la superficie. Esta diferencia en la correlación implica que en el tramo más reciente, por cada metro cuadrado cubierto con edificación, se ofrece menos áreas verdes, con respecto al periodo anterior en el que se mantenía la proporción. La pérdida de proporcionalidad anotada se presenta de una manera más aguda, al bajar al 0,29 cuando se excluye del cálculo los años para los que no se cuenta con una representatividad del $100 \%$ de área de estudio, en el anotado periodo 1971-2013. En síntesis, la relación entre las coberturas 'áreas verdes' y 'área edificada' habría perdido elasticidad en el segundo periodo, lo que contribuyó a la acentuación de la aridez del área de estudio. 
Figura 2. Composición de coberturas en hectáreas

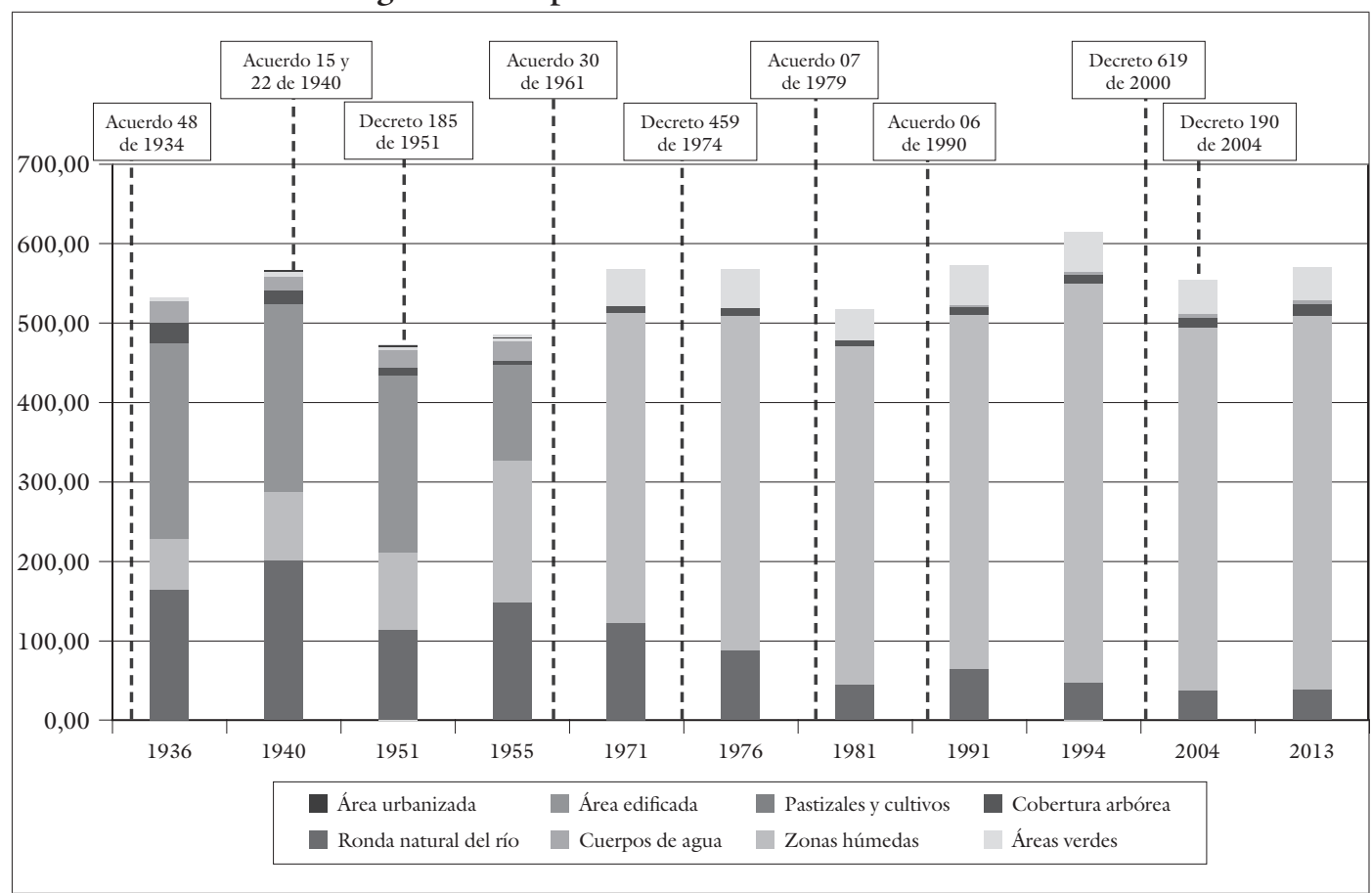

Fuente: Elaboración de los autores.

\section{Establecimiento}

de las unidades de paisaje

Del trabajo de construcción de unidades de paisaje se obtuvo nueve unidades clasificadas de la siguiente manera (mapa 5):

Unidad de paisaje 1. Árida con zonas blandas sobre andén y separador vial: se llama árida porque la mayoría de las manzanas no tienen patios interiores, es decir están casi totalmente edificadas. La vegetación se encuentra en algunas de sus calles, las de mayor sección, que tienen separador con zonas verdes, y alguna vez tuvieron también zonas verdes en los andenes. Las edificaciones varían de altura entre uno y cuatro pisos, siendo el mayor porcentaje dos pisos. Los usos actuales son: residencial con actividad económica y comercio cualificado. Esta unidad de paisaje corresponde al barrio Restrepo Occidental.

Unidad de paisaje 2. Áreas con disminución de zonas blandas: se llama así porque son áreas que originalmente fueron concebidas con una normativa que favorecía las condiciones ecológicas, pero con el tiempo se han cambiado las condiciones del paisaje perdiendo las capas vegetales, debido a las territarias 30 209 
dinámicas sociales y económicas. Los centros de manzana eran ocupados por patios, tenían además antejardines, y en las calles los andenes también tenían zonas blandas y cobertura arbórea. Han cambiado al desaparecer los jardines en los centros de manzana y los antejardines, así como también las zonas blandas en los andenes. Las construcciones que originalmente eran de dos pisos, también han aumentado hasta cuatro pisos. El uso es residencial con comercio y servicios. Esta unidad de paisaje corresponde al barrio Ciudad Jardín sur.

Unidad de paisaje 3. Áreas con antejardín, posible patio interior y zona blanda sobre andén: se llama así porque en muy pocas de sus viviendas se encuentran patios interiores, pero probablemente todas lo tuvieron. Las viviendas tienen una altura de dos a tres pisos, el uso es residencial con comercio y servicios. Corresponden a esta unidad de paisaje el barrio la Fraguita y parte del barrio San Javier.

Unidad de paisaje 4. Áreas áridas: se llama así porque son áreas que no tienen ningún tipo de vegetación ni zona blanda, ni en área privada ni en área pública, no hay antejardines, ni patios interiores, ni zonas verdes sobre los andenes ni separadores con vegetación en las vías. Es decir, están construidas en su totalidad. La altura de las edificaciones puede variar entre dos y siete pisos, concentrándose las mayores alturas en el barrio Restrepo. Los usos corresponden a una zona de comercio cuali- ficado, sobre el barrio mencionado, zona residencial con comercio y servicios en el barrio San Antonio, zona residencial con actividad económica, en los otros barrios, concentrándose en estos el menor número de pisos. Los barrios que corresponden con esta unidad de paisaje son: Restrepo, parte del barrio San Antonio, Buenos Aires, Las Brisas, Modelo Sur, Policarpa, Sevilla y parte de Nariño Sur.

Unidad de paisaje 5. Áreas áridas al interior de la manzana: se llaman así porque no cuentan con zonas blandas o vegetación al interior de la manzana pero sobre el espacio público sí tienen zonas blandas en los andenes. Corresponde a una zona del barrio San Antonio, que probablemente fue construida por otro urbanizador, aparecen además, algunas pequeñas calles peatonales con zonas verdes. La altura de las edificaciones es de dos pisos. El uso es residencial con comercio y servicios.

Unidad de paisaje 6. Áreas con mayor provisión de zonas blandas y diversidad en la cobertura: se llama así porque corresponden a las unidades de paisaje más favorables ecológicamente dentro del área de estudio; cuentan con patios interiores, antejardines, vegetación en andenes, algunas vías peatonales con vegetación, y las vías principales con separadores y vegetación. La altura de las edificaciones es de dos a tres pisos. Pertenecen a esta unidad de paisaje los barrios Ciudad Berna, Caracas, una pequeña parte de San Antonio, parte de Nariño Sur,

\section{territarias 30}


Santa Ana, parte de San Javier, parte de Buenos Aires, Sosiego, Primero de Mayo y Quinta Ramos.

Unidad de paisaje 7. Áreas ocupadas en altura con zonas blandas: esta unidad de paisaje se caracteriza porque cuenta con zonas verdes producto de las áreas de cesión del conjunto. Las edificaciones en promedio tienen una altura de cinco pisos y en su mayoría se encuentran localizadas vecinas al cuerpo de agua. Los usos donde se encuentran localizados son: residencial neta, residencial con actividad económica, de comercio cualificado, residencial con comercio y servicios. Se encuentran en diferentes barrios del área de estudio, predominando la cercanía al cuerpo de agua.

Unidad de paisaje 8. Áreas ocupadas en altura sin zonas blandas: esta unidad de paisaje consta de edificios de altura promedio de cinco pisos que no cuentan con zonas verdes por ser construidos como unidades, no como conjuntos. Están localizadas en diferentes partes del área de estudio, incluyendo la zona de comercio cualificado donde se confunden con edificios comerciales o hacen parte de un uso mixto.

Unidad de paisaje 9. Áreas con antejardín: se llaman así porque cuentan con antejardín pero sin patio interior ni zonas blandas en andén. Corresponden a esta unidad de paisaje los barrios Calvo Sur y parte de $\mathrm{Na}$ riño Sur. Las edificaciones tienen una altura entre uno y dos pisos. El uso es residencial con comercio y servicios.

\section{Análisis de edificabilidad}

Para establecer si el grado de aridez es explicado por los actos administrativos mediante los cuales se aprobó, en un primer momento, la urbanización y la edificación de las unidades de incorporación de suelos de expansión al área urbana, se comparó el índice de ocupación de previsto en estos con el estado actual del mismo índice, registrado por la información catastral. Como resultado de esta comparación se observó que dos de las ocho unidades de paisaje consideradas, registran un índice de ocupación inferior al autorizado en los respectivos actos administrativos. Las restantes seis superan el índice autorizado en los actos de aprobación, en cuantías que oscilan entre el 0,07 y el 0,54, correspondiendo las mayores diferencias a unidades caracterizadas como áridas. Esta diferencia sugiere que el grado de aridez que se observa en la actualidad no estaba previsto en los actos de aprobación inicial y que esta se podría deber a la inobservancia de la norma, es decir, que no se trata de una aridez resultado de la planificación inicial (figura 3).

En relación con la capacidad de la regulación para conducir el ordenamiento del territorio, resulta pertinente revisar los resultados, con el propósito de establecer si la norma anticipa los hechos o se ajusta a estos. Al respecto, resulta significativo que, de los ocho tipos de unidad de paisaje estudiados, dos presenten índices de edificabilidad, calculados con base en la información catastral, es decir, actuales, superiores a los autorizados por la regulación vigente al territarias 30 211 


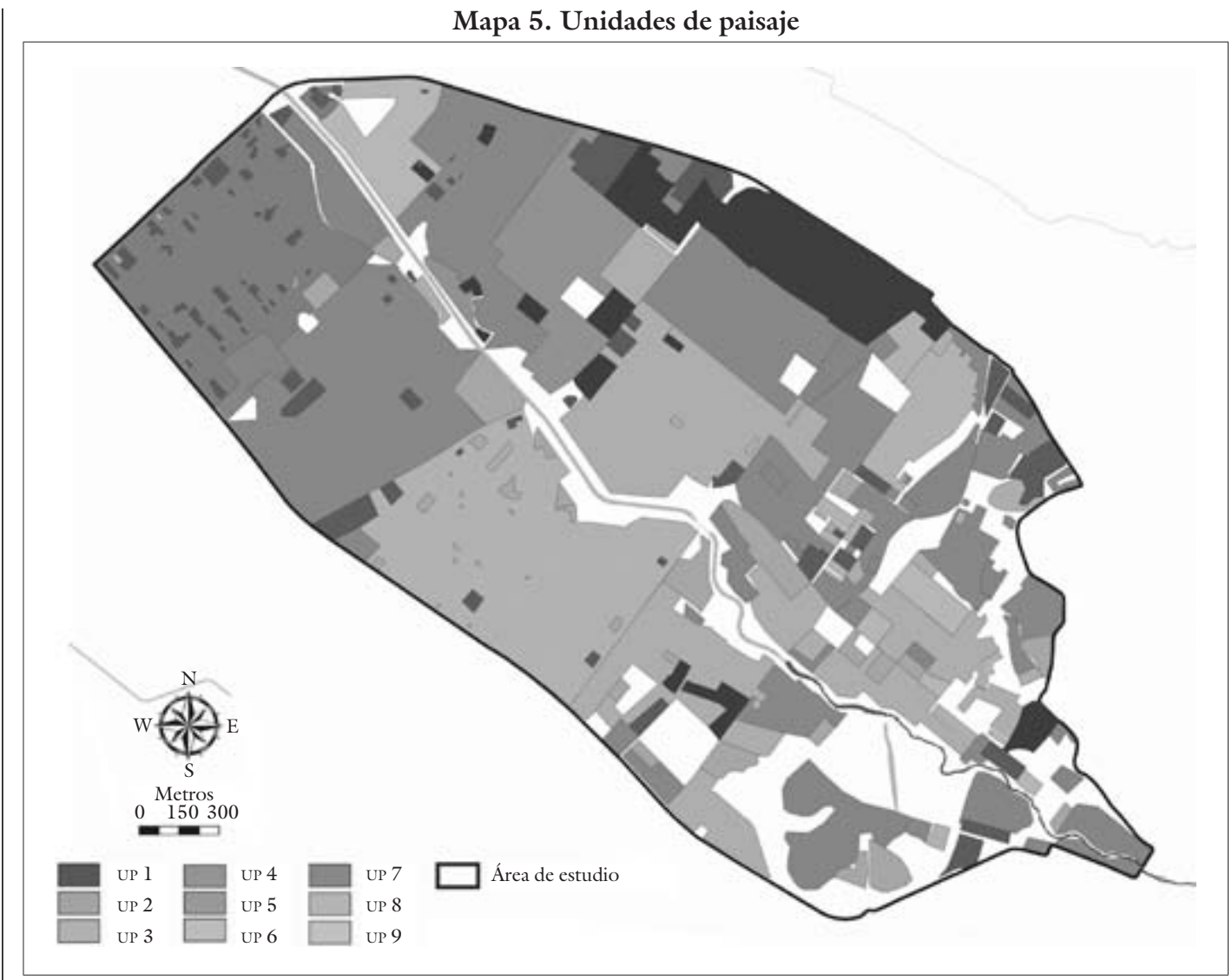

Fuente: Grupo de investigación "Compacidad urbana y restauración ecológica: zona de transición entre la cuenca alta y media del río Fucha (Bogotá, Colombia)”.

Tabla 5. Distribución de unidades de paisaje

del territorio, de acuerdo con los respectivos instrumentos de planificación. También resulta significativo que estos se encuentren entre los tipos de unidad de paisaje de ma- momento de llevar a cabo el análisis. Esta diferencia implicaría que la norma no ofrece, en estos casos, incentivos para que los agentes privados transformen la ocupación

\begin{tabular}{|c|c|c|c|c|c|}
\hline UP 4 & UP 5 & UP 6 & UP 7 & UP 8 & UP 9 \\
\hline
\end{tabular}

Fuente: Grupo de investigación "Compacidad urbana y restauración ecológica: zona de transición entre la cuenca alta y media Fuente: Grupo de investigacion "Comp (Bogotá, Colombia)". 
Figura 3. Índice de ocupación. De la unidad de paisaje más árida a la menos árida

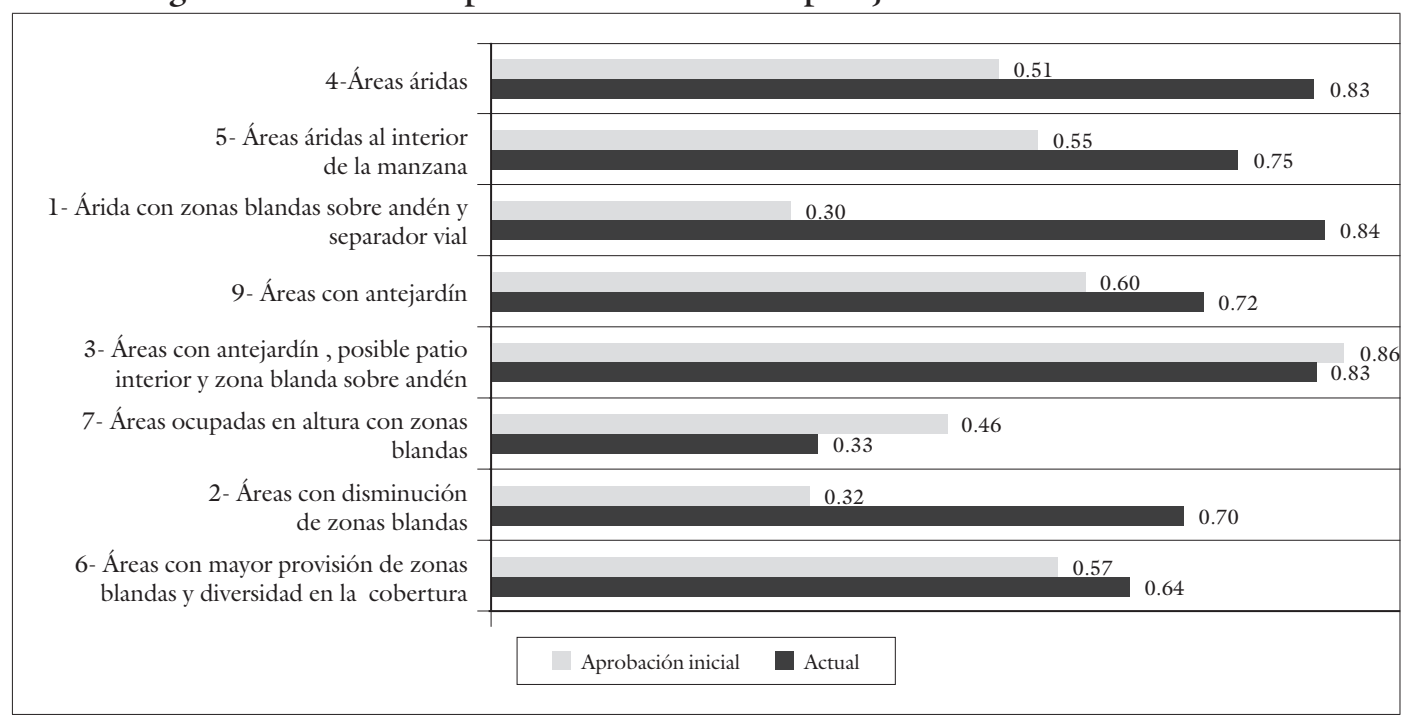

Fuente: Elaboración de los autores.

yor aridez. Estas cifras indicarían que, al menos en estos casos, la regulación carece de capacidad anticipatoria (figura 4).

Ahora bien, estas dudas sobre la capacidad de la regulación, para conducir la ocupación del territorio, se pueden trasponer a lo que cabría esperar con respecto a la aridez, a partir de la misma comparación entre la edificabilidad registrada por la información catastral y la autorizada por la norma vigente al inicio del análisis. Sobre este particular, llama la atención la autorización de índices de 1,22 para dos de los tipos de unidad de paisaje que se encuentran entre los cuatro más áridos, lo mismo que para uno de los correspondientes a los cuatro menos áridos. Lo anterior indicaría que la presión ejercida por las expectativas de edificación sobre la aridez, no es tenida

BIENES Y SERVICIOS ECOSISTÉMICOS EN LA PLANIFICACIÓN Y GESTIÓN DE ÁREAS URBANAS CONSOLIDADAS en cuenta por el instrumento de planificación que la asigna. Por otra parte, los cuatro tipos de unidad de paisaje menos áridos registran incrementos entre el índice actual y el autorizado, que oscilan entre 0,23 y 0,55 , por lo que resulta razonable suponer que esta presión amenaza la provisión de suelos privados capaces de soportar coberturas que ofrezcan bienes y servicios ecosistémicos.

Estas consideraciones indicarían que la denominación 'tratamiento de consolidación' resulta un eufemismo para una regulación reactiva y que es de esperar una acentuación de la aridez, por lo que es pertinente la identificación de instrumentos, tanto de planificación como de gestión, capaces de evitarlo.

tersitarios 30

213 
Figura 4. Índice de edificabilidad. De la unidad de paisaje más árida a la menos árida

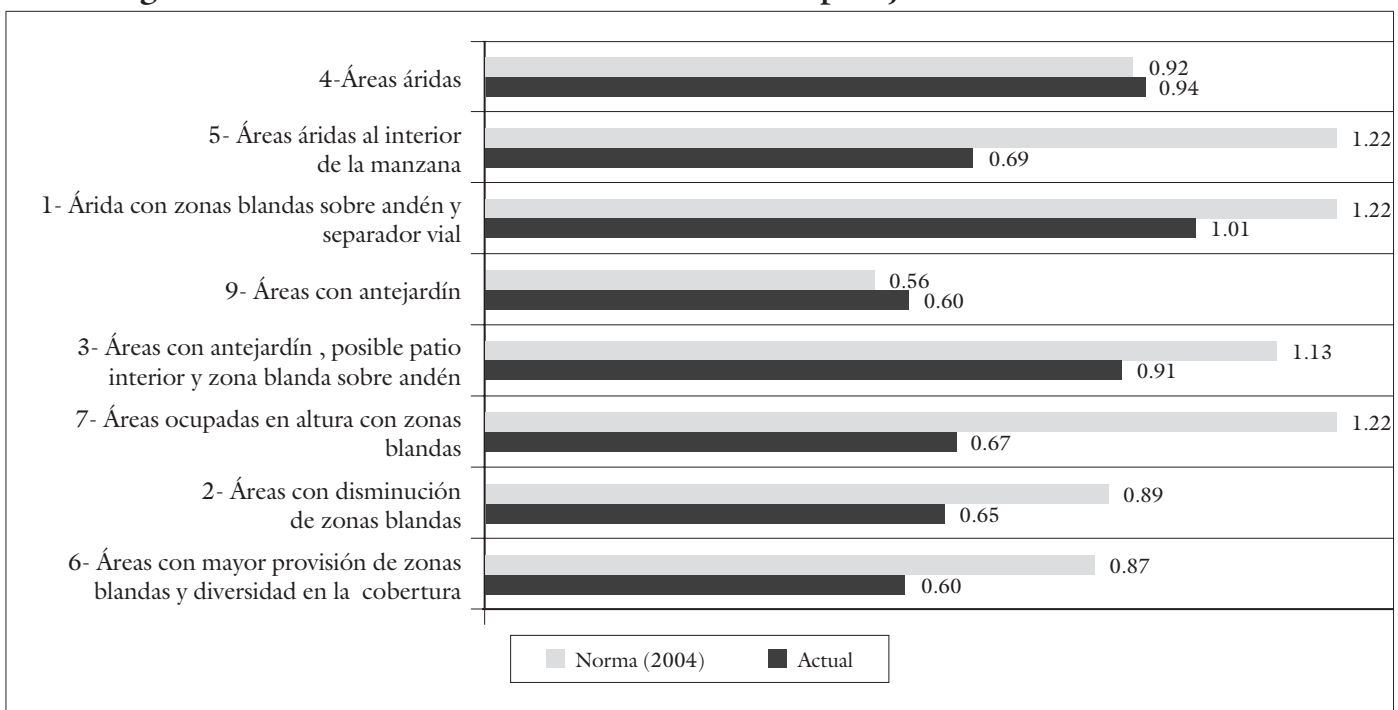

Fuente: Elaboración de los autores.

\section{Discusión}

Los resultados sugieren que los instrumentos de planeación, que asignaron los índices de ocupación y la edificabilidad inicial, a las unidades de incorporación de suelos de expansión al área urbana, entre las décadas de los treinta y cincuenta, proyectaron una ocupación suburbana. Esta caracterización de los patrones iniciales de ocupación se apoya en la observación de aprobaciones de alturas de solo un piso e índices de ocupación tan bajos como de 0,3 , en unidades de paisaje que hoy se encuentran entre los cuatro tipos de mayor aridez, dentro de los estudiados.

El patrón suburbano de ocupación, también de acuerdo con los resultados, cambió en las autorizaciones de urbaniza- ción y edificación, otorgadas a partir de la década de los ochenta, las cuales admitieron alturas de cinco pisos e índices de ocupación de hasta 0,7. El patrón correspondiente a estas autorizaciones debería haber preservado la provisión de suelos blandos, susceptibles de soportar una cobertura que ofrezca bienes y servicios ecosistémicos, al menos en los casos de índices situados entre 0,5 y 0,6 . En el mismo periodo, se observa también menores superficies por lote (llega a mínimos de $60,00 \mathrm{~m}^{2}$ ), en patrones de ocupación continuos de baja altura, en algunos casos construidos sin autorización previa y objeto de actos administrativos de regularización a posteriori como el barrio Policarpa, un caso de subdivisión urbana de origen ilegal; familias desplazadas por la violencia bipartidista de los años cin- 
cuenta invadieron los terrenos aledaños al hospital de La Hortúa en 1961, en 1966 fue nuevamente invadido por otras familias desplazadas y finalmente, después de procesos de consolidación social y urbanística, el barrio fue legalizado con la Resolución 217 de 1986. Estos nuevos patrones, más urbanos que suburbanos, coinciden con la época de mayor crecimiento poblacional de la ciudad de la cual hace parte el segmento de cuenca estudiada. ${ }^{23}$

La asociación con la estructura del sistema de planificación para el ordenamiento del territorio se entiende a través de cuatro aspectos que en la práctica no se asocian, la reglamentación de los territorios a través de usos y tratamientos, los sistemas estructurantes naturales y artificiales que garanticen la conectividad funcional, los instrumentos de planificación-gestión a escala sectorial (planes parciales) y los instrumentos de gestión del suelo para garantizar las coberturas.

El tratamiento de consolidación ofrece la disposición de normas urbanísticas adecuadas para el manejo diferenciado de áreas con desarrollo definido y estable, que oriente el afianzamiento y el mantenimiento de las estructuras urbanas bajo un parámetro de equilibrio y coherencia entre la intensidad de uso del suelo y el sistema de espacio público. Esto, en teoría, se lograría a través de la formulación de la UPZ que, dentro de su estructura, contiene un aspecto ambiental indicativo. Sin embargo, el eje regulador es de carácter inmobiliario, de aprovechamiento urbanístico, que impulsa la densificación predio a predio desconociendo la capacidad de soporte y el sacrificio de suelo potencial de densificaciones coherentes a la provisión de suelo para la devolución de servicios ecosistémicos.

\section{Conclusiones}

Las regulaciones sobre la volumetría, en particular del índice de ocupación resultaron insuficientes para evitar la creciente aridez de las unidades de paisaje estudiadas, puesto que si bien podrían haber evitado la edificación total de la superficie de los predios sujetos a estas, no habrían limitado la disminución de la superficie con cobertura vegetal y su reemplazo por superficies impermeables.

Se requiere replantear el tratamiento de 'consolidación' para asegurar la provisión de suelos blandos, susceptibles de soportar una cobertura que ofrezca bienes y servicios ecosistémicos

Se requiere articular instrumentos específicos para la gestión de la cobertura, que arbitren recursos de los agentes que afectan de manera negativa la provisión de bienes y servicios ecosistémicos y aquellos que se encuentran en condiciones de contribuir a esta.

La degradación ambiental de áreas urbanas que podrían cumplir un papel como ecosistemas estratégicos, ameritan un tratamiento urbanístico que restaure sus funciones ambientales, que afiance y mantenga las estructuras urbanas, pero bajo un parámetro de coherencia entre densificación y provisión de bienes y servicios ecosistémicos. Lo anterior, sugiere el desarrollo de
23 "Entre 1900 y 1930 la población de Bogotá se triplicó y su área urbanizada se multiplicó por ocho [...] Entre 1938 y 1999 la cantidad de población se multiplicó diecinueve veces. La extensión física de Bogotá, en ese mismo lapso, se multiplicó apenas doce veces, lo que indica una inversión del fenómeno de comienzos del siglo $X X$ ” (Saldarriaga, 2006, p. 87). "3. Planes soporte de la acción financiera e inmobiliaria, correspondiente con las tres últimas décadas del siglo $X X[\ldots]$ es el periodo de las grandes inversiones inmobiliarias y también de la conversión de la ciudad en un mosaico de unidades de rentabilidad. Esta tendencia corresponde con la 'ciudad fragmentada' como se reconoce e algunos trabajos recientes" (Saldarriaga, 2006, p. 89).

territarias 30

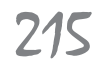


indicadores de diseño urbano que involucre la función ambiental en el aprovechamiento urbanístico y estrategias de gestión que involucren: gravar la destrucción de ecosistemas y la contaminación con participación en las cargas; compensación por acciones para la generación de suelo para recuperación ambiental; y retribución por acciones para la conservación de bienes y servicios ecosistémicos. El esquema requiere un soporte institucional robusto, coordinado y eficiente, que determine las competencias específicas de las instituciones a cargo de los elementos ecológicos y urbanísticos estructurantes.

\section{Referencias}

Alberti, M. (2007). Ecological signatures: the science of sustainable urban forms. Places, 19(3), 56-60. Recuperado de http://www.escholarship.org/uc/ item/6nvl x61b

Alcaldía Mayor de Bogotá, Secretaría Distrital de Planeación. Decreto 190. Por medio del cual se compilan las disposiciones contenidas en los Decretos Distritales 619 de 2000 y 469 de 2003 (junio 22 de 2007).

Alcaldía Mayor de Bogotá, Secretaría Distrital de Planeación. Decreto 619. Por el cual se adopta el Plan de Ordenamiento Territorial para Santa Fe de Bogotá, Distrito Capital. (28 de julio de 2000).

Barreto, P. A. y Montejo, D. A. (2013). Efectos de la ocupación del suelo urbano sobre las comunidades de aves de la zona de transición entre la cuenca alta y media del río Fucha (Bogotá Colombia). (Tesis de grado, Universidad Distrital Francisco José de Caldas, Bogotá, Colombia, inédita).

Beatly, T. (2009). Biophilic Urbanism: Inviting nature back to our communities and into our lives. William \& Mary Environmental Law \& Policy Review, 34(1). Recuperado de http://scholarship.law.wm.edu/wmelpr/vol34/ iss $1 / 6$

Carmona, M. (2000). The Regional Dimension of the Compact City Debate: Latin America. En M. Jenks y R. Burgess (eds.), Compact cities. Sustainable urban forms for devoloping countries (pp. 53-62). Londres y Nueva York: Spon Press.

Cheng, V. (2010). Understanding Density and High Density. En E. Ng (ed.), Designing high-density cities for social and enviromental sustentability (pp. 3-17). Londres: Earthscan.

Departamento Administrativo Nacional de Estadísticas. Estratificación Socioeconómica para Servicios Públicos Domiciliarios. Recuperado de http://www. dane.gov.co/index.php/estratificacionsocioeconomica/generalidades

Díaz, P. (2013). Influencia de los patrones de ocupación y urbanización del territorio en la desecación del suelo en la Sabana de Bogotá: el caso del río Fucha. Revista Nodo, 15(8), 97-117.

Diaz, A. y Armesto, J. (2003). La conservación de las aves silvestres en ambientes urbanos de Santiago. Revista ambiente y desarrollo de CIPMA, 2(19), 31-38. 
Erdas Inc. (2001). Capítulo 12. Ortorectificación. En Erdas tour gide. Recuperado de http://docencia.izt.uam.mx/ hcg/231199/practicas/12_Ortorectificacion.pdf

Estrada, Alfonso. (2013). Impacto del proceso de urbanización sobre la cuenca del río Fucha (Bogotá, Colombia). Working paper.

González-García, A. y Gómez, A. (2008). Private urban green spaces or "patios" as a key element in the urban ecology of tropical Central America. Human Ecology, 36, 291-300. Recuperado de http:// www.jstor.org/stable/27654281

Instituto Geográfico Agustín Codazzi (2003). Gestión del suelo urbano en el marco del ordenamiento territorial. Bogotá: Autor.

Jenks, M. (2000). Sustainable Urban Form in Developing Countries? En M. Jenks \& R. Burgess (eds.), Compact cities. Sustainable urban forms for devoloping countries (pp. 53-62). Londres y Nueva York: Spon Press.

Lemus, V. (2006). Planificación y control urbanístico en Bogotá: desarrollo histórico y jurídico. Bogotá: Editorial Universidad del Rosario.

Meza, L. (2009). Contribución de los jardines domésticos urbanos a la cobertura vegetacional de Santiago de Chile (Tesis de maestría, Pontificia Universidad Católica de Chile, Santiago de Chile, Chile). Recuperado de http://www.estudiosurbanos.uc.cl/wp-content/uploads/ 2012/06/ContribucindelosJardinesDomsticosLuisAdrinMezaMoya.pdf
Molina-Prieto, L. y Vargas-Gómez, O. (juliodiciembre, 2012). Gestión estratégica de la arborización urbana: beneficios ecológicos, ambientales y económicos a nivel local y global. Revista Soluciones de Postgrado EIA, (9), 39-61.

Montenegro, G. (2009). Ciclos normativos legibles desde el paisaje urbano. Ponencia presentada en el Coloquio Instituto de vivienda y urbanismo, Injaviu: Renovación, rehabilitación o expansión urbana. Pontificia Universidad Javeriana.

Osorio-Olarte, J. (2012). Aves migratorias neotropicales en parques y jardines de Bogotá: 1945-2005. Revista Nodo, 6(12), 67-82.

Reyes-Paecke, S. y Meza, L. (2011). Jardines residenciales en Santiago de Chile: Extensión, distribución y cobertura vegetal. Revista Chilena de Historia Natural, 84(4), 581-592.

Reyes-Paecke, S. y Figueroa, I. (2010). Distribución, superficie y accesibilidad de las áreas verdes en Santiago de Chile. Revista Eure, 36(209), 89-110.

Rogers, R. y Gumuchdjian, P. (2008). Ciudades sostenibles. En G. Gili, Ciudades para un pequeño planeta (25-63). Barcelona: Editorial Gustavo Gili.

Rueda, S., De Cáceres, R., Cuchí, A. y Brau, L. (2012). El urbanismo ecológico. Su aplicación en el diseño de un ecobarrio en Figueres. Barcelona: BCNecología.

Rueda, S. (1997). La ciudad compacta y diversa frente a la conurbación difusa. Ciudades para un futuro más sostenible. Recuperado de http://habitat.aq.upm. es/cs/p2/a009.html territarias 30 217 
Saldarriaga, A. (2006). Bogotá siglo XX. Urbanismo, arquitectura y vida urbana. Bogotá: Alcaldía Mayor de Bogotá.

Smith, R., Gaston, K. J., Warren, P. H. y Thompson, K. (2005). Urban domestic gardens $(\mathrm{V})$ : relationships between landcover composition, housing and landscape. Landscape Ecology, 20(2), 235-253.
Recuperado de http://link.springer. com/article/10.1007\%2Fs10980-0043160-0\#page-1

Vélez, L. (2007). La conservación de la naturaleza urbana. Un nuevo reto en la gestión ambiental de las ciudades para el siglo XXI. Revista Bitácora Urbano Territorial, 11(1), 20-27. 